\title{
Particulate Hot Gas Stream Cleanup Technical Issues
}

\author{
Quarterly Report \\ April 1 - June 30, 1997
}

Work Performed Under Contract No.: DE-AC21-94MC31160

\author{
For \\ U.S. Department of Energy \\ Office of Fossil Energy \\ Federal Energy Technology Center \\ P.O. Box 880 \\ Morgantown, West Virginia 26507-0880
}

By

Southern Research Institute

2000 Ninth Avenue South

Post Office Box 55305

Birmingham, Alabama 35255-5305 


\section{Disclaimer}

This report was prepared as an account of work sponsored by an agency of the United States Government. Neither the United States Government nor any agency thereof, nor any of their employees, makes any warranty, express or implied, or assumes any legal liability or responsibility for the accuracy, completeness, or usefulness of any information, apparatus, product, or process disclosed, or represents that its use would not infringe privately owned rights. Reference herein to any specific commercial product, process, or service by trade

name, trademark, manufacturer, or otherwise does not necessarily constitute or imply its endorsement, recommendation, or favoring by the United States Government or any agency thereof. The views and opinions of authors expressed herein do not necessarily state or reflect those of the United States Government or any agency thereof. 


\section{TABLE OF CONTENTS}

$\underline{\text { PAGE }}$

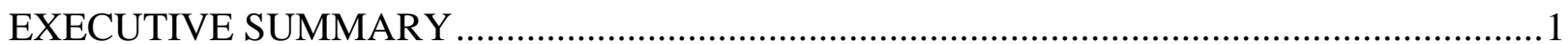

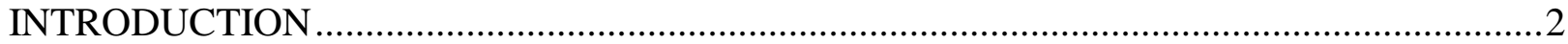

TASK 1 ASSESSMENT OF ASH CHARACTERISTICS ….........................................

TASK 2 FILTER MATERIAL CHARACTERIZATION ............................................... 16

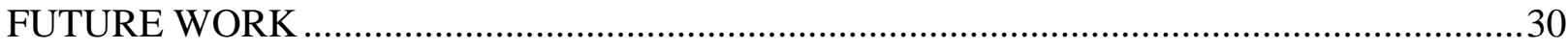

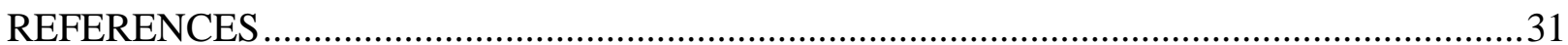




\section{EXECUTIVE SUMMARY}

This is the eleventh in a series of quarterly reports describing the activities performed under Contract No. DE-AC21-94MC31160. Analyses of Hot Gas Stream Cleanup (HGCU) ashes and descriptions of filter performance address aspects of filter operation that are apparently linked to the characteristics of the collected ash or the performance of the ceramic barrier filter elements. Task 1 is designed to generate a data base of the key characteristics of ashes collected from operating advanced particle filters (APFs) and to relate these ash properties to the operation and performance of these filters. Task 2 concerns testing and failure analysis of ceramic filter elements.

Under Task 1 during the past quarter, analyses were completed on samples obtained during a site visit to the Power Systems Development Facility (PSDF). Analyses are in progress on ash samples from the Advanced Particulate Filter (APF) at the Pressurized Fluidized-Bed Combustor (PFBC) that was in operation at Tidd and ash samples from the Pressurized Circulating Fluid Bed (PCFB) system located at Karhula, Finland. An additional analysis was performed on a particulate sample from the Transport Reactor Demonstration Unit (TRDU) located at the University of North Dakota Energy and Environmental Research Center. A manuscript and poster were prepared for presentation at the Advanced Coal-Based Power and Environmental Systems '97 Conference scheduled for July 22 - 24, 1997. A summary of recent project work covering the mechanisms responsible for ash deposit consolidation and ash bridging in APF's collecting PFB ash was prepared and presented at FETC-MGN in early July. The material presented at that meeting is included in the manuscript prepared for the Contractor's Conference and also in this report.

Task 2 work during the past quarter included mechanical testing and microstructural examination of Schumacher FT20 and Pall 326 as-manufactured, after 540 hr. in service at Karhula, and after $1166 \mathrm{hr}$. in service at Karhula. Key test results showed that property degradation occurred during service at Karhula but less degradation than was seen in Schumacher F40 and Pall 442T. Creep continues to be observed in tests at $1600{ }^{\circ} \mathrm{F}$ and above and was observed at $1562^{\circ} \mathrm{F}$ in service at Karhula. Microstructural evaluations of FT20 and 326 materials have shown that the behavior of these materials is controlled by the ceramic binders and that the binders are still glass limited. These results were presented in a poster session and a paper written for the Advanced Coal-Based Power and Environmental Systems '97 Conference. 


\section{INTRODUCTION}

This is the eleventh quarterly report describing the activities performed under Contract No. DE-AC21-94MC31160. Task 1 of this contract concerns analyses of HGCU ashes and descriptions of filter performance that are designed to address the problems with filter operation linked to the characteristics of the collected ash. Task 2 of this contract includes characterization of new and used filter elements. Some of the problems observed at PFBC facilities include excessive filtering pressure drop, the formation of large, tenacious ash deposits within the filter vessel, and bent or broken candle filter elements. These problems have been attributed to ash characteristics, durability of the ceramic filter elements, and specific limitations of the filter design. In addition to the problems related to the characteristics of PFBC ashes, laboratory characterizations of gasifier and carbonizer ashes have shown that these ashes also have characteristics that might negatively affect filtration. Problems with the durability of the filter elements are being addressed by the development and evaluation of elements constructed from alternative ceramic materials.

To identify which ash characteristics can lead to problems with filtration, over 250 particulate samples from thirteen facilities involved in FETC's HGCU program have been assembled. Samples from gasification studies being carried out by Herman Research Pty Ltd. (HRL) of Melbourne, Australia have also been included in the data base. Many of these samples have been analyzed with a variety of laboratory tests. Physical attributes of the particles that have been examined include size distribution, specific surface area, particle morphology, and bulk ash cohesivity and permeability. A range of chemical analyses on these samples, as well as characterizations of agglomerates of particles removed from filter vessels at Tidd, Karhula and Foster Wheeler's pilot-scale combustion facility located in Livingston, New Jersey have also been performed. The data obtained in these studies are being assembled into an interactive data base which will help the manufacturers and operators of high-temperature barrier filters tailor their designs and operations to the specific characteristics of the particulate materials they are collecting.

In order to understand the thermal and mechanical behavior of the various types of ceramic materials used in hot gas filtration, hoop and axial tensile tests, thermal expansion, compression, and creep evaluations of these materials at temperatures up to $1800^{\circ} \mathrm{F}$ have been performed. Nondestructive testing methods performed on filter specimens include density and ultrasonic velocity. To date various characteristics of Dupont/Lanxide PRD-66, Dupont composite, 3M composite, IF\&P Fibrosics, Refractron, Schumacher, and Blasch ceramic materials have been evaluated.

Task 1 has two primary objectives. The first is to generate a readily accessible data base of the key characteristics of ashes collected from operating advanced particle filters. The second objective is to relate these ash properties and the contents of the data base to the operation and performance of the advanced particle filters and filter components. The first objective includes formatting the data base and collecting, analyzing, and maintaining ashes from operating HGCU facilities. The second objective of this task involves the collection of 
operating histories from advanced particle filters, correlating these histories with ash characteristics, interpreting these correlations, and communicating results in the various venues prescribed by DOE/FETC-MGN.

The objectives of the Task 2 test program at Southern Research are as follows:

1. Provide material characterization to develop an understanding of the physical, mechanical, and thermal behavior of hot gas filter materials.

2. Develop a material property data base from which the behavior of materials in the hot gas cleanup environment may be predicted.

3. Perform testing and analysis of filter elements after exposure to actual operating conditions to determine the effects of the thermal and chemical environments in hot gas filtration on material properties.

4. Explore the glass-like nature of the matrix material. 


\section{TASK 1 ASSESSMENT OF ASH CHARACTERISTICS}

Analyses were completed on samples obtained during a site visit to the Power Systems Development Facility (PSDF). Analyses are in progress on ash samples from the Tidd PFBC and the Karhula PCFB. An additional analysis was performed on a particulate sample from the TRDU located at the University of North Dakota Energy and Environmental Research Center. A summary of recent project work covering the mechanisms responsible for ash deposit consolidation and ash bridging in APF's collecting PFB ash was prepared and presented at FETC-MGN in early July. The material presented at that meeting is included in this report. A manuscript and poster were prepared for presentation at the Advanced CoalBased Power and Environmental Systems '97 Conference scheduled for July 22 - 24, 1997. The samples characterized during the past quarter and discussed in this report are briefly described in Table 1.

Table 1

Particulate Samples Characterized during the Past Quarter

\begin{tabular}{|l|l|l|}
\hline ID \# & \multicolumn{1}{|c|}{ Source } & \multicolumn{1}{c|}{ Brief description } \\
\hline \hline 4199 & TRDU & PO50 filter vessel hopper ash: $1 / 14 / 97$ \\
\hline 4231 & PSDF & filter cake ash: 4/9/97 \\
\hline 4067 & Karhula PCFB & filter cake ash - middle plenum: 1-2/94 \\
\hline 4182 & Karhula PCFB & filter cake ash - middle plenum: spring 96 \\
\hline 4049 & Tidd PFBC & ash from baghouse hopper: $1 / 94$ \\
\hline 4087 & Tidd PFBC & ash from deposit under tubesheet - middle plenum: 5/5/94 \\
\hline 4088 & Tidd PFBC & ash from deposit under tubesheet - bottom plenum: $5 / 5 / 94$ \\
\hline 4143 & Tidd PFBC & filter cake ash - top plenum: 5/11/95 \\
\hline 4144 & Tidd PFBC & filter cake ash - top plenum: 5/11/95 (bottom of candles) \\
\hline
\end{tabular}

The results of most of the the various physical and chemical analyses performed on the samples listed in Table 1 are presented in Tables 2 and 3. (Some of these results have been presented previously and are included to support the discussions presented in this report.) 
Table 2

Physical Characteristics ofTRDU and PSDF Ashes

\begin{tabular}{|l|c|c|}
\hline \multicolumn{1}{|c|}{ Source } & TRDU & PSDF \\
\hline Quantity \# & 4199 & 4231 \\
\hline \hline specific surface area, $\mathrm{m}^{2} / \mathrm{g}$ & 105.3 & 3.80 \\
\hline Stokes' MMD, $\mu \mathrm{m}$ & 2.4 & 4.7 \\
\hline uncompacted bulk porosity, \% & 89 & 85 \\
\hline filter cake porosity, \% & -- & 87 \\
\hline drag-equivalent diameter, $\mu \mathrm{m}$ & 0.719 & 2.05 \\
\hline $\begin{array}{l}\text { specific gas flow resistance, } \\
\text { in } \mathrm{H}_{2} \mathrm{O} \cdot \mathrm{min} \cdot \mathrm{ft} / \mathrm{lb}\end{array}$ & -- & 1.6 \\
\hline $\begin{array}{l}\text { specific gas flow resistance, } \\
\text { in } \mathrm{H}_{2} \mathrm{O} \cdot \mathrm{min} \cdot \mathrm{ft} / \mathrm{lb} *\end{array}$ & 8.5 & 2.6 \\
\hline tensile strength, $\mathrm{N} / \mathrm{m}^{2}$ & 5.7 & -- \\
\hline true particle density, $\mathrm{g} / \mathrm{cm}^{3}$ & 2.26 & 2.61 \\
\hline
\end{tabular}

* calculated for an actual filter cake porosity

** calculated for a filter cake porosity equal to the uncompacted bulk porosity

Table 3

Chemical Composition of Tidd, Karhula, TRDU, and PSDF Ashes, \% wt.

\begin{tabular}{|c|c|c|c|c|c|}
\hline Source & Tidd & Tidd & Karhula & TRDU & PSDF \\
\hline Constituent & 4087 & 4144 & 4182 & 4199 & 4231 \\
\hline $\mathrm{Li}_{2} \mathrm{O}$ & 0.01 & 0.01 & 0.01 & 0.01 & 0.027 \\
\hline $\mathrm{Na}_{2} \mathrm{O}$ & 0.34 & 0.29 & 0.87 & 0.90 & 0.52 \\
\hline $\mathrm{K}_{2} \mathrm{O}$ & 1.6 & 1.3 & 1.6 & 0.18 & 1.73 \\
\hline $\mathrm{MgO}$ & 8.7 & 8.3 & 0.72 & 11.0 & 2.12 \\
\hline $\mathrm{CaO}$ & 13.2 & 14.1 & 17.4 & 44.0 & 4.49 \\
\hline $\mathrm{Fe}_{2} \mathrm{O}_{3}$ & 5.3 & 7.1 & 11 & 9.0 & 5.10 \\
\hline $\mathrm{Al}_{2} \mathrm{O}_{3}$ & 12.2 & 11.7 & 12.6 & 15.1 & 21.89 \\
\hline $\mathrm{SiO}_{2}$ & 24.3 & 26.1 & 34.4 & 12.9 & 57.25 \\
\hline $\mathrm{TiO}_{2}$ & 0.5 & 1.2 & 0.6 & 1.7 & 1.15 \\
\hline $\mathrm{P}_{2} \mathrm{O}_{5}$ & 0.08 & 0.15 & 0.1 & 1.0 & 0.32 \\
\hline $\mathrm{SO}_{3}$ & 32 & 30.1 & 19.8 & 1.9 & 2.53 \\
\hline LOI & 5.1 & 13.5 & 0.22 & 54.2 & 7.80 \\
\hline soluble $\mathrm{SO}_{4}=$ & 39.1 & 29.7 & 23.8 & 0.98 & -- \\
\hline Equilibrium $\mathrm{pH}^{*}$ & 5.8 & -- & 7.4 & 10.87 & -- \\
\hline silica ratio $* *$ & 47 & 47 & 54 & 17 & 67 \\
\hline $\mathrm{R}_{\mathrm{b} / \mathrm{a}} * *$ & 0.79 & 0.80 & 0.66 & 2.19 & 0.17 \\
\hline
\end{tabular}


Site Visit to the PSDF and PSDF Ash Analyses

The Westinghouse filter installed on the M.W. Kellogg reactor train at the PSDF was opened on April 9 because of indications of filter element breakage. A site visit was made to the PSDF on that date to observe, document and characterize the filter cakes present on the candle filter elements and other filter vessel deposits when the filter vessel was opened for refitting. All of the candle filter elements were covered with patchy, thin cakes. The thickness of the filter cakes ranged from about 0.1 to $1 \mathrm{~mm}$. (Because the filter was extensively pulse-cleaned prior to shutdown, the thickness of these cakes does not necessarily represent the condition of the cakes during operation.) Analyses were performed on filter cake ash that was collected from the surfaces of the candles before they were removed from the tubesheet. Two complete candles with deposited filter cakes were also set aside for ash analysis. Analyses of the filter cake ash and filter cake nodules obtained from two candles that were set aside for ash analysis are summarized in Tables 2 and 3.

Filter cake porosity was measured for nodules from the PSDF filter cake by impregnating weighed filter cake nodules with ethanol. This method yielded an average porosity of $87 \%$ (a relatively high value for non-gasification filter cakes). The uncompacted bulk porosity is also relatively high indicating that this ash, at least initially, should form rather porous filter cakes. The drag-equivalent diameter derived from permeability measurements performed on a bulk sample of this ash indicates that filter cakes with moderate porosities should not exhibit excessive filtering pressure drops. This statement is supported by the relatively low specific surface area of the ash $\left(3.80 \mathrm{~m}^{2} / \mathrm{g}\right)$, even though it has a relatively fine size distribution $(\mathrm{MMD}=4.7 \mu \mathrm{m})$. The specific gas-flow resistance of this ash is presented for the actual measured filter cake porosity and for a filter cake porosity equal to the uncompacted bulk porosity. (Uncompacted bulk porosity is used as an estimate of filter cake porosity if the latter quantity cannot be directly measured.) Both values of permeability are quite low.

Because no sorbents were added to the process stream during the generation of this ash (ID \# 4231), the concentrations of calcium and magnesium in this ash are relatively low (as compared with pressurized, fluidized-bed combustion ashes from fully implemented processes). Consequently, the bulk mineral analysis of this ash (see Table 2) is similar to those of coal ashes produced in pulverized coal-fired boilers. Because operation of the PSDF combustor is still in its early stages, the chemical and physical characteristics of PSDF ashes produced in later operation must continue to be monitored.

\section{Analyses of TRDU Ash}

Most of the analyses performed on sample \# 4199 were discussed in the most recent quarterly report (covering January - March 1997). One additional measurement (tensile strength) was performed on this sample during the current reporting period. The tensile strength of this 
sample $\left(5.7 \mathrm{~N} / \mathrm{m}^{2}\right)$ is low to moderate, indicating that this ash may tend to reentrain after being dislodged by back pulsing.

Analyses of Tidd and Karhula Ashes

Ash bridging in high temperature filters collecting PFBC ashes has been linked to the formation in the filter vessels of ash nodules with high inherent strength. Nodules with this characteristic have been collected from several PFBC filters, including Karhula and Tidd (where ash bridging has been well documented). To determine whether nodule formation could be simulated in the laboratory, an experiment was performed to see if baking uncompacted beds of Tidd and Karhula ashes at $1600{ }^{\circ} \mathrm{F}$ could induce the beds to consolidate and strengthen. A test performed and reported in our most recent quarterly report demonstrated that some consolidation could be achieved for some ashes with simple baking for 72 hours in room air at $1600{ }^{\circ} \mathrm{F}$. The samples used for this experiment were ID \#'s 4088, 4143, 4067, and 4182. The Tidd ashes consolidated slightly (about $3 \%$ loss in volume for the filter cake ash and about $10 \%$ loss in volume for the ash from the tubesheet deposit). The Karhula ashes did not measurably decrease in volume. The ashes were then baked for an additional 168 hours, but no additional losses in volume were observed for any of the samples.

A second set of baking experiments was performed during the current reporting period to more carefully control and monitor the water content of the samples throughout the baking process. Two Tidd ash samples (ID \# 4049 and ID \# 4088) were sifted into open cups. After their porosity was determined, they were dried for about 5 hours at $500^{\circ} \mathrm{F}$. After baking, some shrinkage was noted for sample \# 4088; however, the loss in overall sample volume roughly corresponded to the loss in weight the samples experienced during baking at $500{ }^{\circ} \mathrm{F}$. In other words, sample \# 4088 decreased in volume, but its porosity remained essentially unchanged. The baking process was then continued by exposing the samples to $1600{ }^{\circ} \mathrm{F}$ for 1 week. Both samples lost weight and volume (about a $27 \%$ decrease for the tubesheet deposit ash, and a $17 \%$ decrease for the hopper ash). As was observed after baking at $500{ }^{\circ} \mathrm{F}$, the loss in volume for these samples roughly corresponded to their loss in weight. Further tests are planned to assess the role of water loss in consolidation measurements, to identify the temperatures needed to remove all the hydrated water from the ash samples prior to baking, and to determine the consolidation potential of ashes that have been thoroughly dried prior to sifting them into the open cups used for the baking and consolidation measurements.

The ash deformation test commonly run on ashed coal samples during standard analyses of coal samples to determine their propensity to foul boiler tubes was performed on Tidd, Karhula, and PSDF ashes. Although this test subjects samples to temperatures up to $2800{ }^{\circ} \mathrm{F}$, (much higher than high-temperature, high-pressure (HTHP) filters ever experience), the temperatures where these ash samples begin to soften might provide a ranking of their tendency to soften and potentially create viscous liquid or near-liquid layers on their surfaces in HTHP filter vessels. The results of these tests are presented in Table 4. 
Table 4

Fusion Temperatures of Selected Ashes in Oxidizing Environments, ${ }^{\circ} \mathrm{F}$

\begin{tabular}{|c|c|c|c|c|c|}
\hline SID & 4143 & 4182 & 4067 & 4088 & 4231 \\
\hline Initial deformation & 2222 & 2150 & 2172 & 2200 & 2275 \\
\hline Softening & 2225 & 2155 & 2178 & 2226 & 2308 \\
\hline Hemispherical & 2230 & 2164 & 2184 & 2237 & 2355 \\
\hline Fluid & 2270 & 2184 & 2207 & 2255 & 2467 \\
\hline
\end{tabular}

The results of these measurements of ash fusion temperatures will be compared with the results of the additional baking tests mentioned above.

Chemical analyses of the ashes are often used to evaluate coals for their propensity to form fouling or slagging deposits in conventional pulverized coal-fired (PC) boilers. A variety of chemical parameters are used in these evaluations. Table 3 includes values calculated for several HGCU ashes of two quantities, the silica ratio and the base-to-acid ratio $\left(\mathrm{R}_{\mathrm{b} / \mathrm{a}}\right)$, that are commonly used for this purpose ${ }^{1}$. The definitions of these two quantities are given below:

silica ratio $=\mathrm{SiO}_{2} \times 100 /\left(\mathrm{SiO}_{2}+\mathrm{Fe}_{2} \mathrm{O}_{3}+\mathrm{CaO}+\mathrm{MgO}\right)$

$\mathrm{R}_{\mathrm{b} / \mathrm{a}}=\left(\mathrm{Fe}_{2} \mathrm{O}_{3}+\mathrm{CaO}+\mathrm{MgO}+\mathrm{K}_{2} \mathrm{O}+\mathrm{Na}_{2} \mathrm{O}\right) /\left(\mathrm{SiO}_{2}+\mathrm{Al}_{2} \mathrm{O}_{3}+\mathrm{TiO}_{2}\right)$

* The silica ratio and the base-to-acid ratio are calculated from the wt \%'s of the various oxides listed in equations 1 and 2 .

Ashes for which the values of silica ratio fall between 50 and 65 are considered to exhibit a high probability of slagging. Values between 65 and 72 indicate some probability of slagging, and values over 72 indicate nonslagging coals. Even though application of the silica ratio is intended for conventional PC boilers, it is clear that the PFBC ashes from Tidd and Karhula could be interpreted as having a very high probability of slagging if present in a PC boiler.

The base-to-acid ratio shown in equation 2 was also calculated for the HGCU ashes in Table 3. For this quantity, a value of 0.5 is sometimes specified as the maximum tolerable value before slagging can be expected to become a problem ${ }^{1}$. As with the silica ratio, the PFBC ashes from Tidd and Karhula could be interpreted as having a very high probability of slagging in a PC boiler environment because of the base-to-acid ratio. It should be noted that the gasification process that generated the TRDU sample (ID \# 4199) may cause the interpretation of ratios based on bulk mineral analyses of ashes expected to be generated in conventional PC combustion to be inapplicable to this gasification particulate sample. Further work planned in this area includes searching for chemical quantities that may be useful for predicting the relative viscosities of ashes from HGCU facilities. 
General Characteristics of Gasification Particulates

Overall, the characteristics of the gasification samples that have been evaluated from the MGCR, TRDU and the HRL Mulgrave test rig are similar to other samples of gasification particulate that have been analyzed previously. (Analyses of these samples have been presented and discussed in previous quarterly reports.) The median size of gasification particles from a given facility is dependent on the design of the facility and the specific operation of the gasification process. The typical characteristics of gasification particulates include irregular particle shapes, high specific surface areas, and relatively high values of uncompacted bulk porosity and specific gas-flow resistance. Filter cakes comprising gasification particulates must maintain relatively porous structures to prevent excessive filtering pressure losses. If these filter cakes compact or consolidate significantly, the effect of the high specific surface area of the particles on pressure drop could be severe. As operating experience with gasification facilities accumulates, the structure of filter cake samples from these facilities will be studied to determine if factors such as differential pressure drop across the cake or exposure time tend to alter the structure of the cake.

Because the relationships between chemical constituents and particulate behavior are not yet established for gasification particulate, the effect on filtration behavior of the various chemical compounds present in gasification particulate samples are not yet known. Chemical reactions such as tar formation and chemical sintering between particles have the potential to create serious problems such as bridging in filters collecting gasification particulates.

Mechanism Describing the Consolidation of Ash Deposits in PFBC Filters

SEM photographs that have been presented in previous reports of fresh fracture surfaces of filter cake nodules taken from the filters at Tidd and Karhula demonstrate that the nodules found in these filters are concretions composed of discrete fine particles almost completely embedded in pervasive amorphous masses. These masses apparently form in the filter vessel after the particles are initially collected. The appearance of these nodules, in combination with other laboratory analyses of ash deposits from Grimethorpe, Tidd, and Karhula, and a review of the effects of ash chemistry on particle bonding has allowed the development of the following description of the mechanism responsible for the consolidation of ash deposits in PFBC filter vessels.

The formation of strong, consolidated ash deposits begins with direct contacts between collected particles comprising highly concentrated, dissimilar chemical compounds. Chemical species exist in high local concentrations in particles collected in HGCU filters applied to PFBC processes because of the nature of the process. In conventional pulverized coal combustion, the fly ash particles are generated through carbon burnout, melting, or vaporization/condensation processes. These latter two mechanisms produce individual ash particles containing a broad array of chemical compounds. In the PFBC process, the coal and sorbent particles introduced into the combustor are never exposed to high enough temperatures to undergo either significant rapid melting, or vaporization and condensation. The chemical compositions of the entrained particles that leave the boiler result from either carbon burnout around mineral inclusions in the coal, or carryover of alkaline sorbent particles that have been mostly sulfated in the combustor. Therefore the individual particles 
entering the HGCU filter are much more likely to be predominantly composed of a single compound. Distinct chemical compositions of various individual particles found in ash deposits obtained from the Tidd APF have been observed with SEM microprobe analyses ${ }^{2}$. Consequently the ash deposits in a PFBC HGCU filter contain a high proportion of intimate interparticle contacts between highly concentrated, distinct chemical compounds.

Although HGCU temperatures are not high enough to melt these concentrated compounds, solid-to-solid diffusion gradually occurs between dissimilar compounds in direct contact. The formation of interparticle melts resulting from these direct contacts is shown generically in Figure 1. As the compounds diffuse together in the region of particle contact, compositions are eventually obtained that begin to melt at the HGCU operating temperature. (The points corresponding to these compositions are labeled $\mathrm{C}_{1}$ and $\mathrm{C}_{2}$ in Figure 1.) The interparticle melts that form act as fluxing agents, speeding the diffusion of chemical species into the region of interparticle contact. Eventually, the composition of the interparticle melt reaches the eutectic composition, which is established by minimizing the overall system energy for the combination of compounds involved in the process. The eutectic composition is the particular combination of the compounds that yields the minimum melting point. The melting point of the eutectic is lower, often by a significant amount, than the melting points of any of the chemical compounds contained in the eutectic composition.

Therefore, any adjacent particles that place two distinct compounds in direct contact will tend toward the formation of a eutectic at the interparticle contact point. The rate at which the eutectic composition is approached is determined by several factors. These include the purity of the component compounds, the geometry of the interparticle contact (particle size and contact area), the pressure of contact between the particles, the temperature of the particles, and the fluxing action of intermediate compositions of the component compounds. In addition, other factors that exist in HGCU filters may also influence the rate of eutectic formation. These include the presence of gaseous compounds in the pressurized flue gas surrounding the particles, and additional compounds that are probably present in relatively low concentrations in the contacting particles. (In general, the melting point of a eutectic will be further decreased by the addition of more chemical species into the eventual eutectic composition.)

Based on the nature of the PFBC process and the measured bulk compositions (see Table 3) of various ash samples obtained from APFs at PFBC facilities, there are several compounds that are likely to be available in PFBC ash deposits. Some of the compounds that may be found in high concentrations in individual PFBC ash particles include $\mathrm{K}_{2} \mathrm{SO}_{4}, \mathrm{CaSO}_{4}$, $\mathrm{MgSO}_{4}, \mathrm{Na}_{2} \mathrm{SO}_{4}, \mathrm{~K}_{2} \mathrm{O}, \mathrm{MgO}, \mathrm{SiO}_{2}, \mathrm{Al}_{2} \mathrm{O}_{3}$, and $\mathrm{Fe}_{2} \mathrm{O}_{3}$. A review of multicomponent system phase diagrams involving combinations of these compounds was conducted. Table 5 lists systems (combinations of compounds) with eutectic compositions that melt below $1600{ }^{\circ} \mathrm{F}$ and their eutectic melting points. It is evident from the melting points in Table 5 that APFs collecting PFBC ash and operating at or near $1600{ }^{\circ} \mathrm{F}$ probably provide the conditions necessary for the development of melts at many of the interparticle contact points in the various ash deposits formed in the filter. Given enough time, these interparticle melts will develop. 


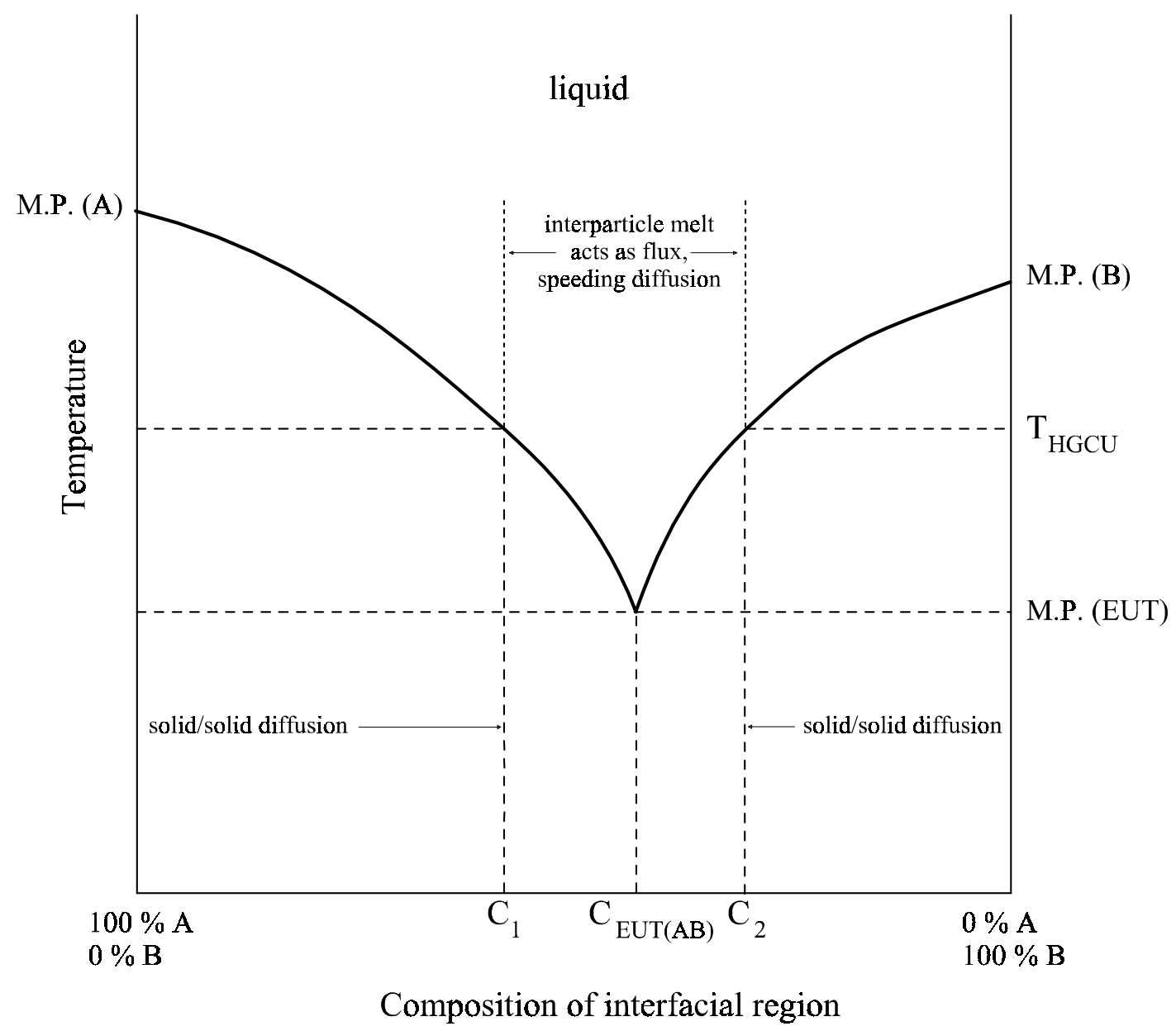

Figure 1. Binary phase diagram showing the formation of eutectic $(\mathrm{AB})$ resulting from surface diffustion between solid compounds $A$ and $B$ in contact. Eutectic $(\mathrm{AB})$ has a melting point less than the temperature of the HGCU filter. Compositions $\mathrm{C}_{1}$ and $\mathrm{C}_{2}$ have melting points equal to the temperature of the HGCU filter. 
Table 5

Systems Containing Compounds that can Combine and Melt Below $1600{ }^{\circ} \mathrm{F}^{3}$

\begin{tabular}{|c|c|c|}
\hline System & Relative Amounts, $\%$ wt. & $\begin{array}{c}\text { Melting Point, } \\
{ }^{\circ} \mathrm{F}\end{array}$ \\
\hline \hline $\mathrm{K}_{2} \mathrm{SO}_{4}-\mathrm{CaSO}_{4}-\mathrm{MgSO}_{4}$ & $70-5-25$ & 1346 \\
\hline $\mathrm{K}_{2} \mathrm{SO}_{4}-\mathrm{MgSO}_{4}$ & $72-28$ & 1382 \\
\hline $\mathrm{K}_{2} \mathrm{SO}_{4}-\mathrm{Na}_{2} \mathrm{SO}_{4}$ & $21-79$ & 1513 \\
\hline $\mathrm{SiO}_{2}-\mathrm{K}_{2} \mathrm{O}-\mathrm{Na}_{2} \mathrm{O}$ & $69-23-8$ & 1004 \\
\hline $\mathrm{K}_{2} \mathrm{SO}_{4}-\mathrm{Na}_{2} \mathrm{SO}_{4}-\mathrm{MgSO}_{4}$ & $15-55-30$ & 1193 \\
\hline $\mathrm{CaSO}_{4}-\mathrm{Na}_{2} \mathrm{SO}_{4}-\mathrm{MgSO}_{4}$ & $5-59-36$ & 1202 \\
\hline $\mathrm{MgO}-\mathrm{Na}_{2} \mathrm{O}$ & $63-8-29$ & 1315 \\
\hline $\mathrm{K}_{2} \mathrm{O}-\mathrm{SiO}_{2}$ & $33-67$ & 1382 \\
\hline
\end{tabular}

As the volume of an interparticle melt grows, the surface capillary force exerted by the surface tension of the liquid melt gradually rearranges the collected particles into a more compact structure. This effect is shown schematically in Figure 2. In addition to the detrimental effects, this consolidation (reduction in the porosity of the deposit) has on filtering pressure losses, the interparticle bonding forces increase, causing the overall deposit to have significantly greater strength.

Because the environment in which a PFBC ash deposit is present in an APF includes all the ingredients necessary to form these detrimental, consolidated deposits, it is important to consider all of the factors that influence the rate at which these deposits will consolidate. The consolidating force, which results from the development of interparticle melts between adjacent particles, is dependent on the particle size, the viscosity and surface tension of the interparticle melt, as well as the time of exposure of the particles to the forces exerted by the surface tension of the melt ${ }^{1,4}$. The size distribution of the particles in the ash deposit is controlled by the parameters of the PFBC process, the characteristics of the coal and sorbent, and the design of the particle filter (and any inertial collectors, if they are included in the collection system). The viscosity and surface tension of the melt are functions of the chemical composition of the melt, and the HGCU temperature ${ }^{1}$. Figure 3 shows the dependence of the dimension of the interparticle melt on particle size ${ }^{1}$. Figure 4 demonstrates that if given sufficient time, even an interparticle melt that is highly viscous at HGCU conditions will eventually cause the formation of particle bonds with significant size ${ }^{1}$. It is evident from these data and the nature of the mechanism governing the formation of consolidated ash deposits in PFBC filters that the time that the collected ash particles are allowed to reside in the APF must be minimized. 


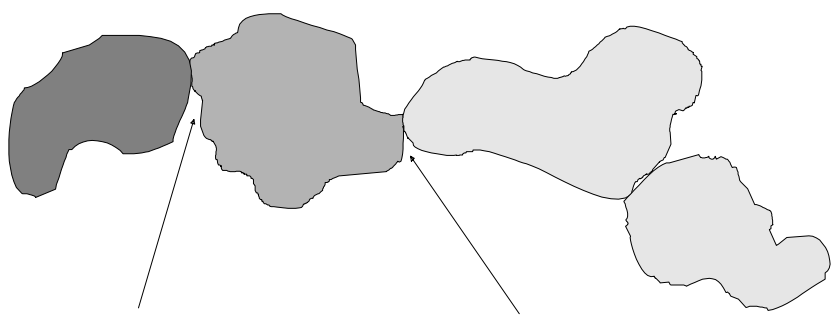

Diffusion of solid compounds occurs at contacts between particles of dissimilar composition.

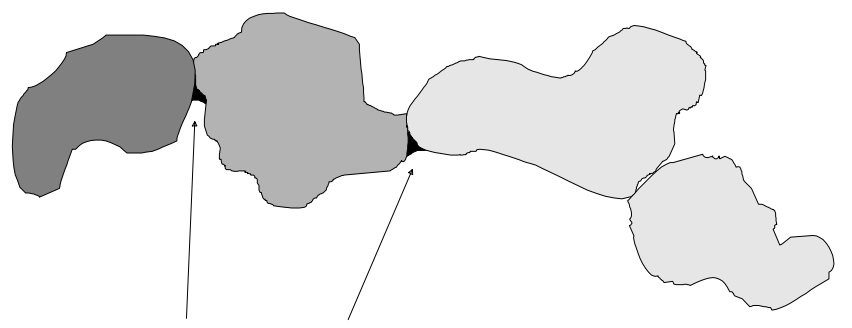

Diffused compounds form interparticle melts.

These melts act as flux, increasing the rate of diffusion.

The surface tension of interparticle melts begins to rearrange particle contacts.

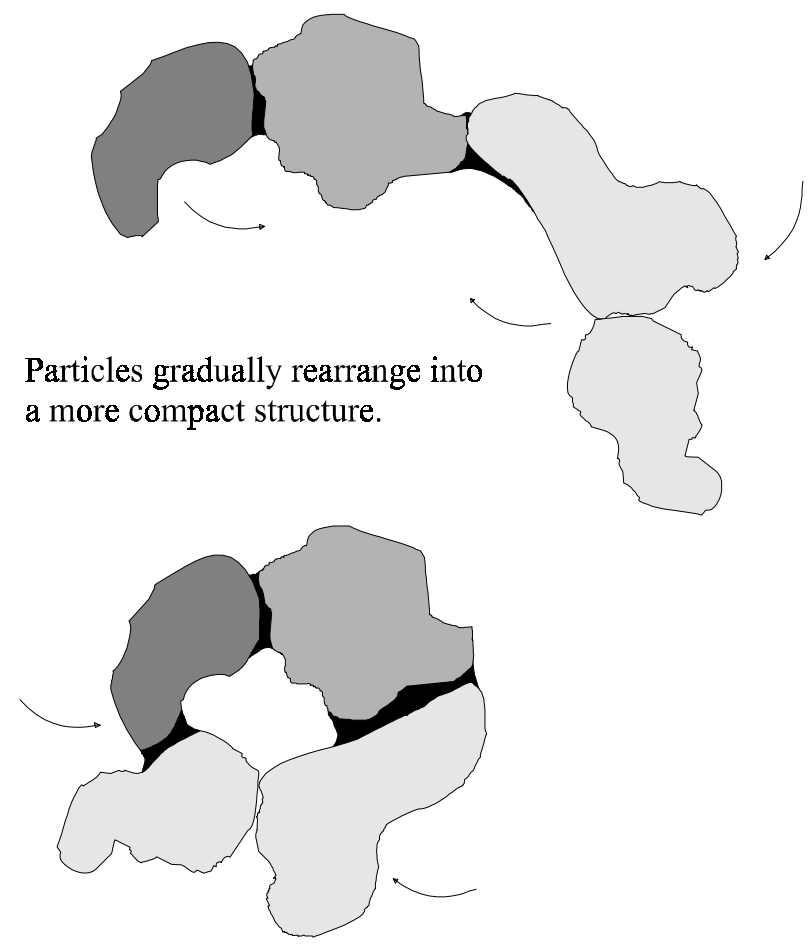

The deposit consolidates. Eutectic melts fill much of the interstitial volume. Particle bonds strengthen.

Figure 2. Schematic representation of the consolidation of ash deposits. 


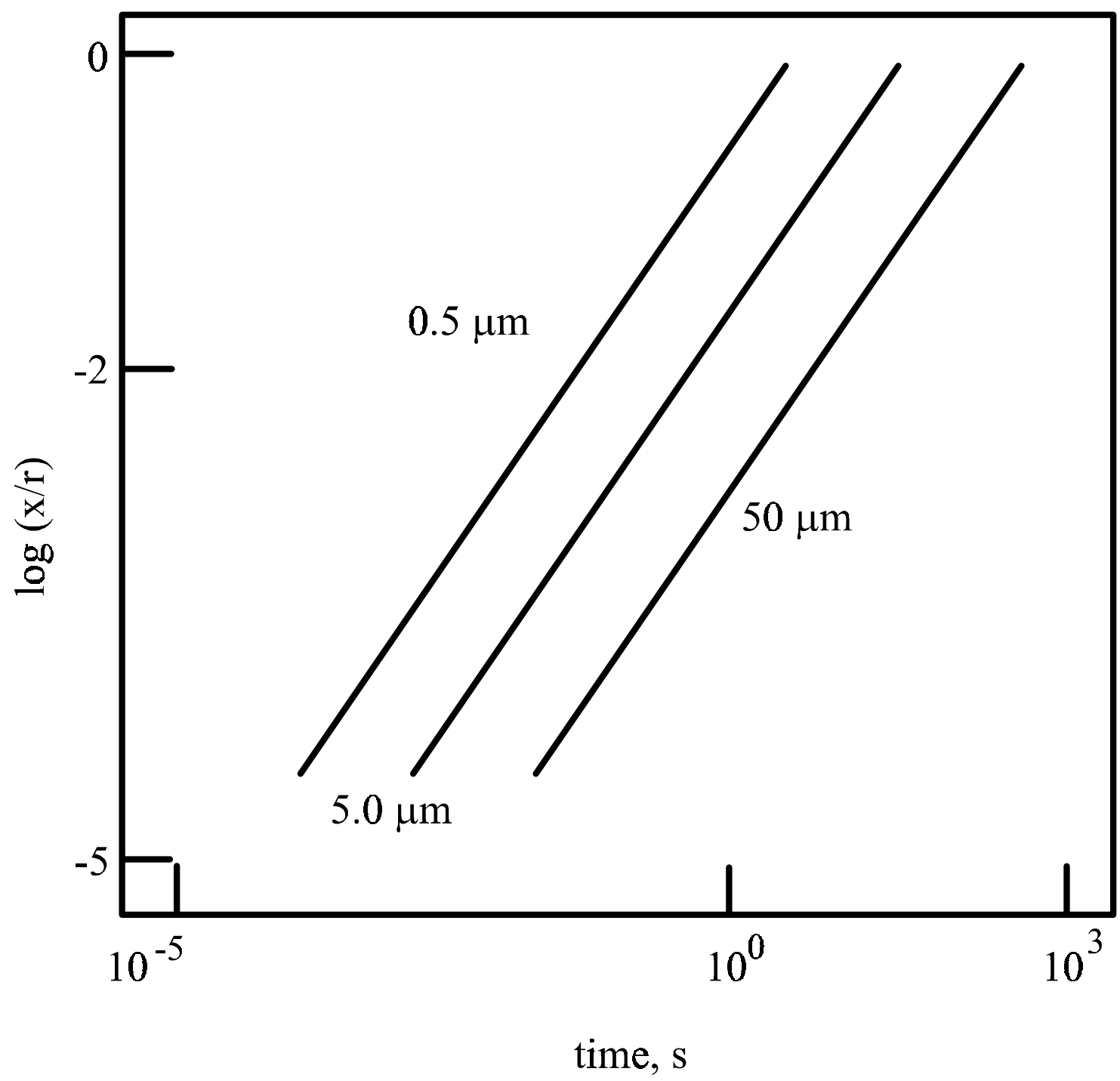

Figure 3. Sintering as a function of time for a range of particle sizes. Sintering is expressed as $\mathrm{x} / \mathrm{r}$, where $\mathrm{x}=$ the radius of the interparticle interface, and $\mathrm{r}=$ the particle radius. 


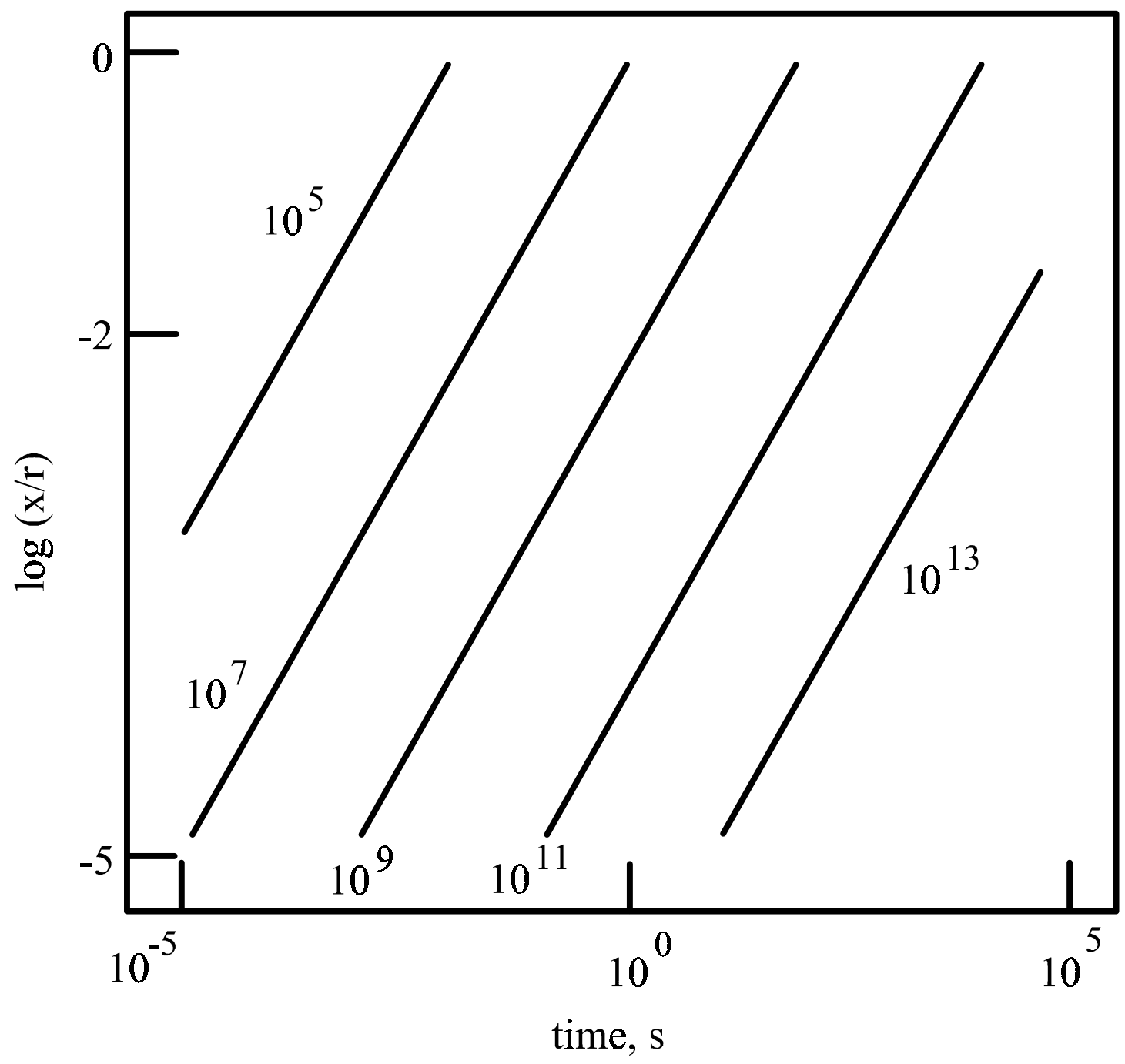

Figure 4. Sintering as a function of time for a range of viscosities. Sintering is expressed as $\mathrm{x} / \mathrm{r}$, where $\mathrm{x}=$ the radius of the interparticle interface, and $\mathrm{r}=$ the particle radius. Values of viscosity are given in poise. 


\section{TASK 2 FILTER MATERIAL CHARACTERIZATION}

Task 2 efforts during the past quarter have focused on Schumacher FT20 and Pall 326 claybonded $\mathrm{SiC}$ particle candle filters. Schumacher F40 and Pall 442T showed substantial creep and degradation of the binder, so new creep resistant candle filters were manufactured with different binders, Schumacher FT20 and Pall 326, that were intended to decrease the creep rate. Testing of these two materials has been conducted according to the test matrices shown in Tables 6 and 7.

Test results on as-manufactured Schumacher FT20 and Pall 326 indicate that the creep rate has indeed been decreased by about an order of magnitude, and the temperature where creep begins to occur has been increased by $100^{\circ} \mathrm{F}$ to $200^{\circ} \mathrm{F}$; however, creep continues to be seen in testing at $1600{ }^{\circ} \mathrm{F}$ and above and was observed at $1562{ }^{\circ} \mathrm{F}$ in service at Karhula. The creep resistance comes at the price of reduced room temperature strength, although the FT20 and 326 materials have nearly the same strength as the F40 and $442 \mathrm{~T}$ materials in the operating temperature range. Axial tensile, hoop tensile, tensile creep, thermal expansion, and thermal conductivity properties were measured on these materials as-manufactured, after $540 \mathrm{hr}$. of PFBC service, and after $1166 \mathrm{hr}$. of PFBC service. Tests performed after PFBC service have provided an indication of these materials' ability to survive long-term in the hot gas cleanup environment.

Testing of FT20 and 326 materials after $540 \mathrm{hr}$. and $1166 \mathrm{hr}$. in PFBC service showed that property degradation occurred but less than was seen in F40 and 442T materials. The stressstrain curves for FT20 and $442 \mathrm{~T}$ at room temperature became nonlinear after service in the PFBC, possibly due to additional porosity and matrix cracks. Microstructural examinations of Schumacher F40 and Pall 326 have been used to provide material models which explain the behavior of these materials. These material models have shown that the behavior of the candle filters is controlled by the ceramic binder. Evidence indicates that the binder in both of these materials is a non-translucent clay with alumina and some free glass (free silica) and that characteristics of glass such as chemical attack in the presence of acid, high temperature creep, and stress rupture will be seen in Schumacher FT20 and Pall 326. Considerable observations indicate that the matrices are still glass limited. 
Table 6

Test Matrix for Pall 326 and Schumacher FT20 Candle Filter Materials

\begin{tabular}{|c|c|c|c|c|c|}
\hline \multirow[b]{2}{*}{ Test Type } & \multirow[b]{2}{*}{ Direction } & \multicolumn{4}{|c|}{ Test Temperature } \\
\hline & & RT & $1600^{\circ} \mathrm{F}$ & $1700^{\circ} \mathrm{F}$ & $1800^{\circ} \mathrm{F}$ \\
\hline \multirow[t]{2}{*}{ Tensile } & Hoop & 9 & & & \\
\hline & Axial & 4 & 4 & 4 & 4 \\
\hline Tensile Creep & Axial & & 4 & 4 & \\
\hline Thermal Expansion & Axial & \multicolumn{4}{|c|}{ 2---------------------------------------------------> } \\
\hline & & & & & \\
\hline Thermal Cond. & Radial & \multicolumn{4}{|c|}{ 2---------------------------------------------------> } \\
\hline Microstructure & & $\mathrm{X}$ & & & \\
\hline
\end{tabular}

Table 7

Test Matrix for Pall 326 and Schumacher FT20 Candle Filter Materials after 540 and 1166 Hours at $1560{ }^{\circ} \mathrm{F}$ in Service at Karhula

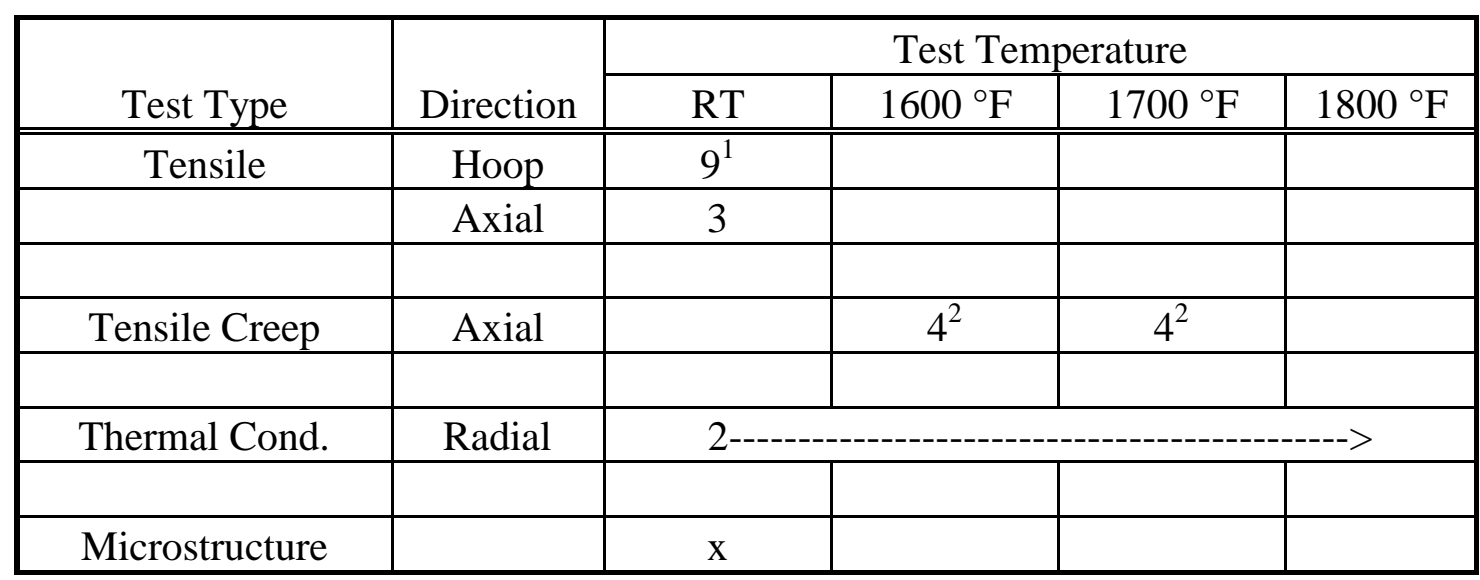

1. Hoop tensile testing was performed only on material with $540 \mathrm{hrs}$. in service.

2. Only one creep specimen was tested after $1166 \mathrm{hrs}$. in service.

Schumacher FT20

One of the key material issues for hot gas filter materials has been strength degradation with time in service. Southern has used room temperature tensile testing on candle filters removed from service to monitor retained mechanical strength. Axial tensile stress-strain responses at room temperature are shown in Figure 5 for Schumacher FT20 as-manufactured, after 540 hrs. at $1560{ }^{\circ} \mathrm{F}$ in service, and after $1166 \mathrm{hrs}$. at $1560^{\circ} \mathrm{F}$ in service. The responses were linear all the way to failure for as-manufactured specimens and became bilinear after service at Karhula. The shape of the curves was about the same for the specimens with $540 \mathrm{hr}$. in 
service as for the specimens with $1166 \mathrm{hr}$. in service. Perhaps the change in stress-strain response was caused by matrix compliance due to lost matrix material after service in the PFBC. Some special work, including microscopic examination of fractured tensile specimens, is needed to fully explain the change in shape of the stress-strain curves.

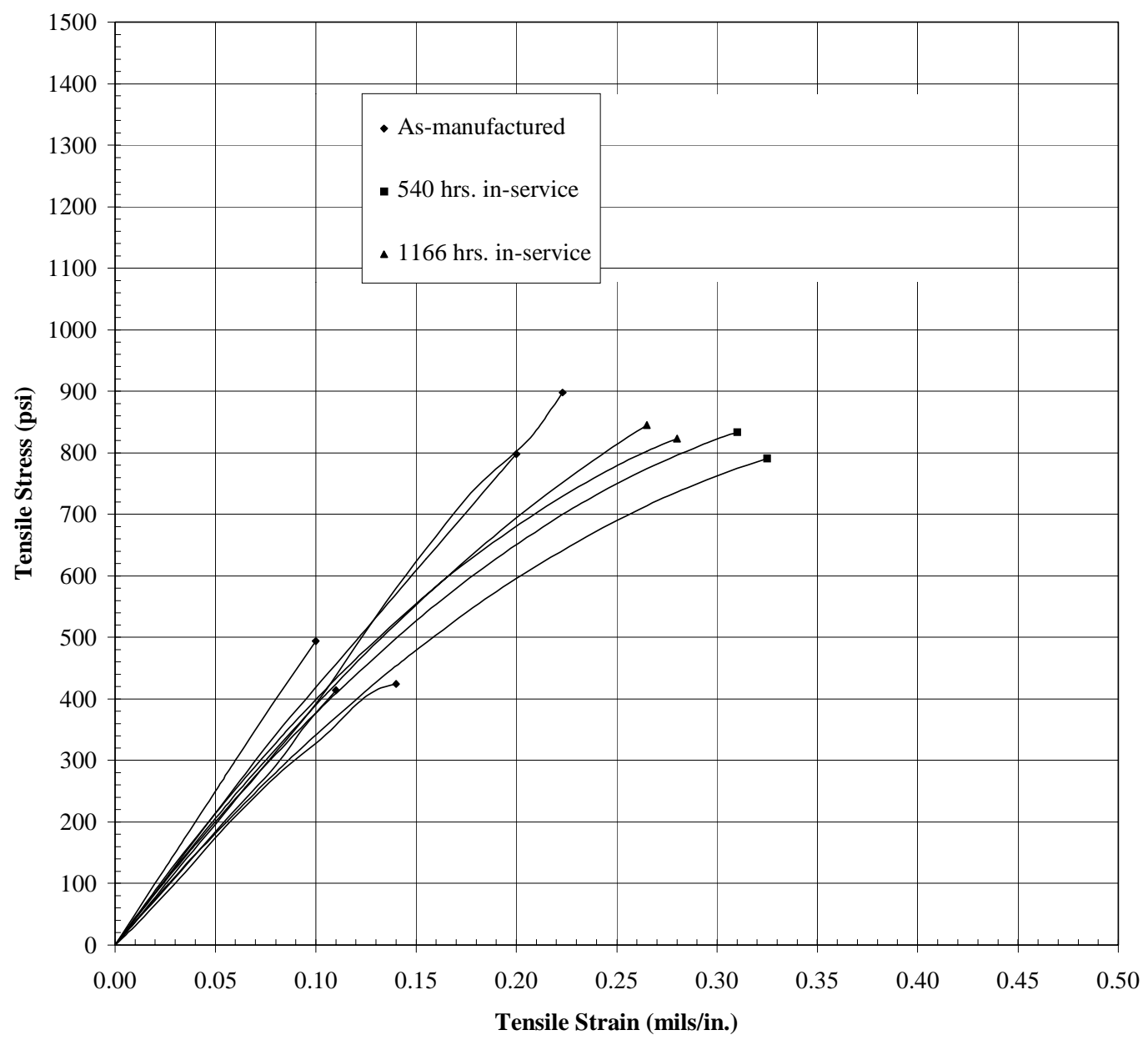

Figure 5. Tensile stress-strain responses at room temperature for Schumacher FT20.

Room temperature tensile strengths in both the axial and hoop directions are plotted versus time in service in Figure 6. The results obtained in the hoop direction indicate a decrease of $\sim 10 \%$ in tensile strength after $540 \mathrm{hr}$. in service. In the axial direction, a large specimen-tospecimen variability was seen in tensile strength of the as-manufactured specimens which made strength comparisons between the different conditions difficult. However, based on the higher strength as-manufactured specimens, the axial tensile strength is near the same after $540 \mathrm{hr}$. or $1166 \mathrm{hr}$. in service at $1560{ }^{\circ} \mathrm{F}$ as in as-manufactured condition. Taken together, the axial and hoop tensile strengths indicate that the tensile strength may decrease slightly, up to $\sim 10 \%$, over the first $540 \mathrm{hr}$. and then remain the same from $540 \mathrm{hr}$. to $1166 \mathrm{hr}$. 


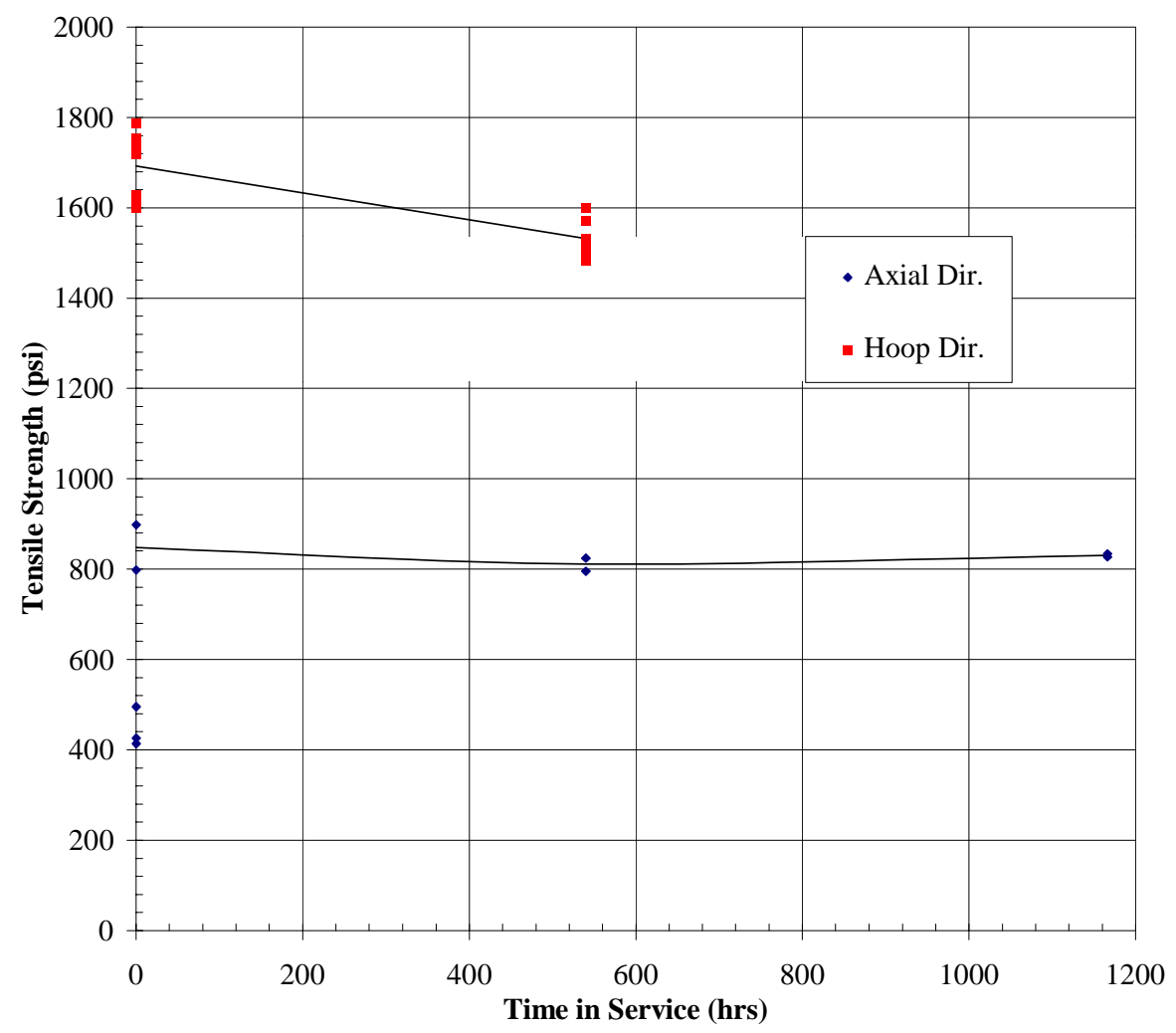

Figure 6. Ultimate tensile strength versus time in service for Schumacher FT20.

Creep strain versus time responses obtained for Schumacher FT20 are shown in Figure 7. The responses consisted of an initial region and a secondary region with the creep rate about an order of magnitude greater in the initial region. The initial creep rate at $1600^{\circ} \mathrm{F}$ ranged from $3.2 \times 10^{-5} \mathrm{in} . / \mathrm{in} . / \mathrm{hr}$. with a $300 \mathrm{psi}$ load to $11.3 \times 10^{-5} \mathrm{in} . / \mathrm{in} . / \mathrm{hr}$. with a $500 \mathrm{psi}$ load. Two secondary creep rates, $1.5 \times 10^{-6} \mathrm{in} . / \mathrm{in} . / \mathrm{hr}$. with a $250 \mathrm{psi}$ load and $2.1 \times 10^{-6} \mathrm{in} . / \mathrm{in} . / \mathrm{hr}$. with a $500 \mathrm{psi}$ load, were obtained at $1600^{\circ} \mathrm{F}$. At $1700^{\circ} \mathrm{F}$, initial creep rates of $5.1 \times 10^{-5}$ in./in./hr. with a load of $250 \mathrm{psi}$ and $14.8 \times 10^{-5} \mathrm{in}$./in./hr. with a load of $500 \mathrm{psi}$ were obtained and one secondary creep rate of $1.0 \times 10^{-5} \mathrm{in}$./in./hr. with a load of $250 \mathrm{psi}$ was obtained. The specimen tested at $1700^{\circ} \mathrm{F}, 500 \mathrm{psi}$ had already been tested at $1600^{\circ} \mathrm{F}, 500$ psi for $114 \mathrm{hrs}$.. The creep response of one Schumacher F40 specimen at $1400^{\circ} \mathrm{F}$ is included in Figure 7 for comparison. As shown, the creep rate of $\mathrm{F} 40$ at $1400^{\circ} \mathrm{F}$ is comparable to the creep rate of FT20 at $1600^{\circ} \mathrm{F}$. Also, note that stress rupture occurred several in several FT20 specimens. 


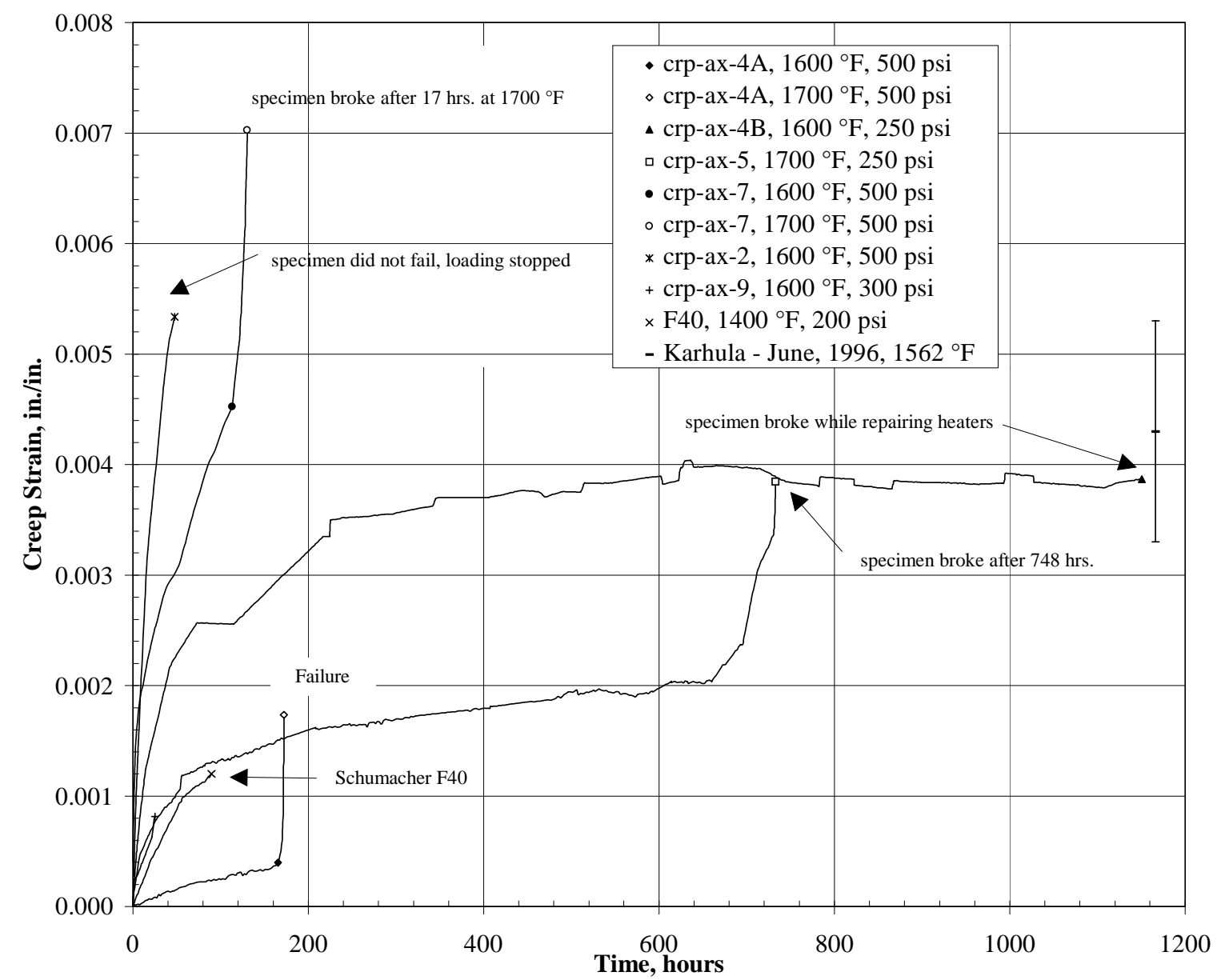

Figure 7. Creep strain versus time for Schumacher FT20.

Westinghouse reported elongation of some candle filters, including Schumacher FT20, after removal from the PCFBC at Karhula in November, 1996 following $1166 \mathrm{hrs}$. of operation at $1560{ }^{\circ} \mathrm{F}$. The elongations measured ranged from $5-8 \mathrm{~mm}(0.2-0.3 \mathrm{in}$.), representing creep strains of $0.0033 \mathrm{in} . / \mathrm{in}$. to $0.0052 \mathrm{in./in..} \mathrm{The} \mathrm{range} \mathrm{of} \mathrm{creep} \mathrm{strains} \mathrm{observed} \mathrm{after} 1166 \mathrm{hrs}$. in service at Karhula is plotted in Figure 7. Direct comparison of the elongations measured after service in Karhula and the creep strains measured in tensile creep tests is difficult because the loads in Karhula are not known; however, the loads in Karhula probably were much smaller than the 250 psi or 500 psi loads used for creep tests. Agreement between the measured creep strains and the measured elongations after service in Karhula appears reasonable, certainly within an order of magnitude, although if the loads in Karhula were indeed smaller than in the creep tests, then less elongation in service at Karhula would be expected based on the measured creep rates. This indicates that the long-term exposure to the hot gas filtration environment may affect the creep behavior of the Schumacher FT20 material. Creep testing of material removed from Karhula currently is in progress and will provide some indication of the effect of the hot gas filtration on creep performance.

The Schumacher FT20 creep specimens were susceptible to stress rupture at $1700{ }^{\circ} \mathrm{F}$. The duration of the $1700^{\circ} \mathrm{F}$ tests before failure occurred ranged from $7 \mathrm{hrs}$. with a 500 psi load to 
$748 \mathrm{hrs}$. with a $250 \mathrm{psi}$ load. Only one specimen failed during creep testing at $1600{ }^{\circ} \mathrm{F}$ and that specimen failed after $25 \mathrm{hrs}$. at $300 \mathrm{psi}$. The failure of creep specimens at $1700{ }^{\circ} \mathrm{F}$ and 500 psi load (or 250 psi for one specimen) might or might not be an important issue, depending on the required operating temperature and the operating loads. If these candles are to operate in the temperature range of $1600{ }^{\circ} \mathrm{F}$ to $1700{ }^{\circ} \mathrm{F}$, then creep testing in the future must determine the maximum temperature and the maximum load level at which the FT20 material can operate without creep failure.

Unit thermal expansion of Schumacher FT20 and F40 are shown in Figure 8.

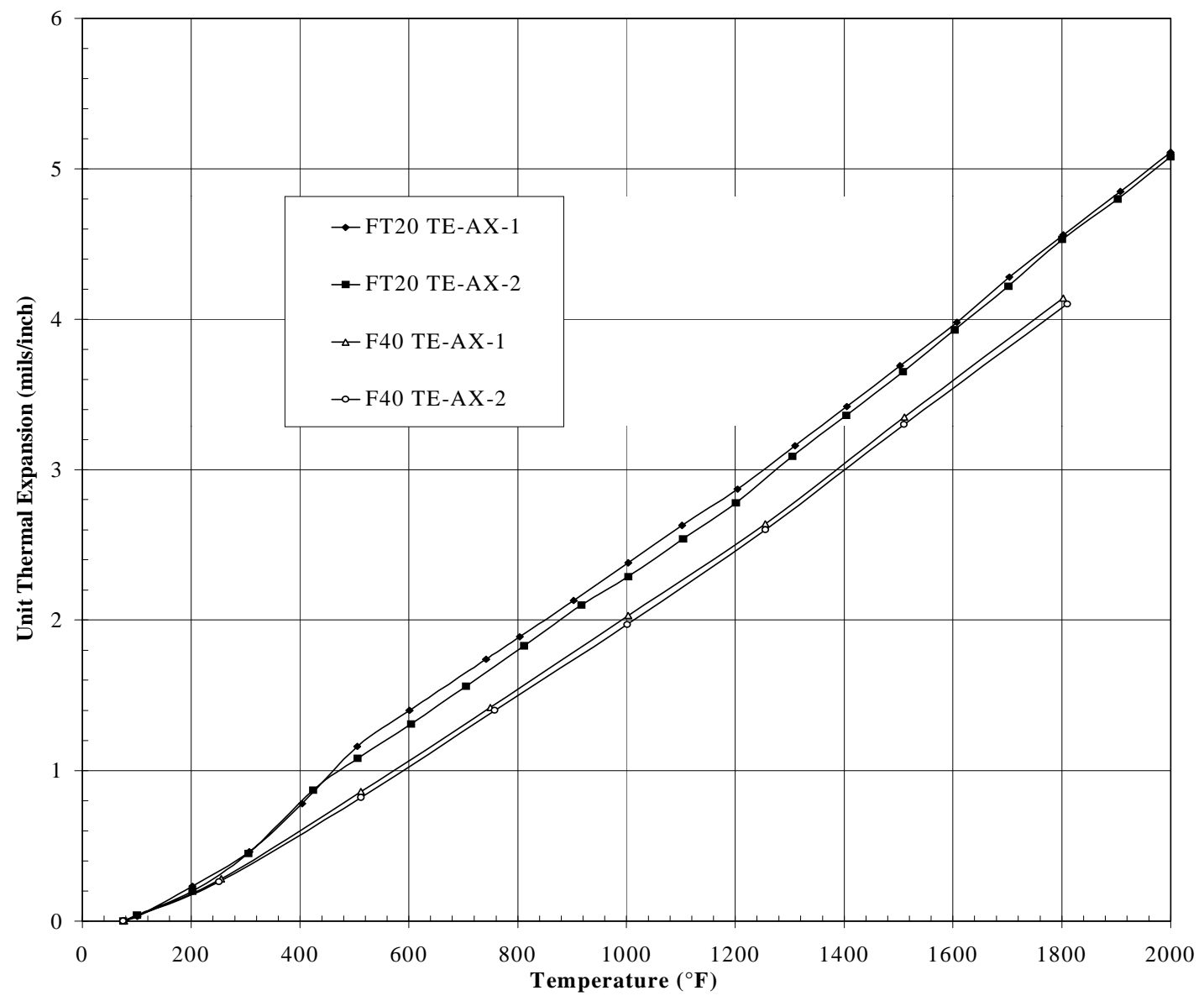

Figure 8. Unit thermal expansion of Schumacher FT20 and F40.

A "knee" in thermal expansion curve for FT20 was seen at $300{ }^{\circ} \mathrm{F}$ to $500{ }^{\circ} \mathrm{F}$ which was not seen for F40. Other ceramics such as pyroceram, cordierite, and quartz-bearing clays show a similar behavior. Return to zero on cool-down indicates that the knee in the curve probably represents a reversible phase transformation. From $500{ }^{\circ} \mathrm{F}$ up, the shape of the thermal curves for FT20 and F40 was similar; therefore, the materials have nearly the same coefficient of thermal expansion (CTE) in the operating range. 
Thermal conductivity of as-manufactured Schumacher FT20 is plotted versus temperature in Figure 9. Thermal conductivity of as-manufactured Schumacher F40 is included for comparison. As shown, the thermal conductivity of Schumacher FT20 decreased from 58 BTU-in./hr-ft ${ }^{2}{ }^{\circ} \mathrm{F}$ at $150{ }^{\circ} \mathrm{F}$ to $\sim 48 \mathrm{BTU}-\mathrm{in} . / \mathrm{hr}-\mathrm{ft}^{2}{ }^{\circ} \mathrm{F}$ at $1500{ }^{\circ} \mathrm{F}$.

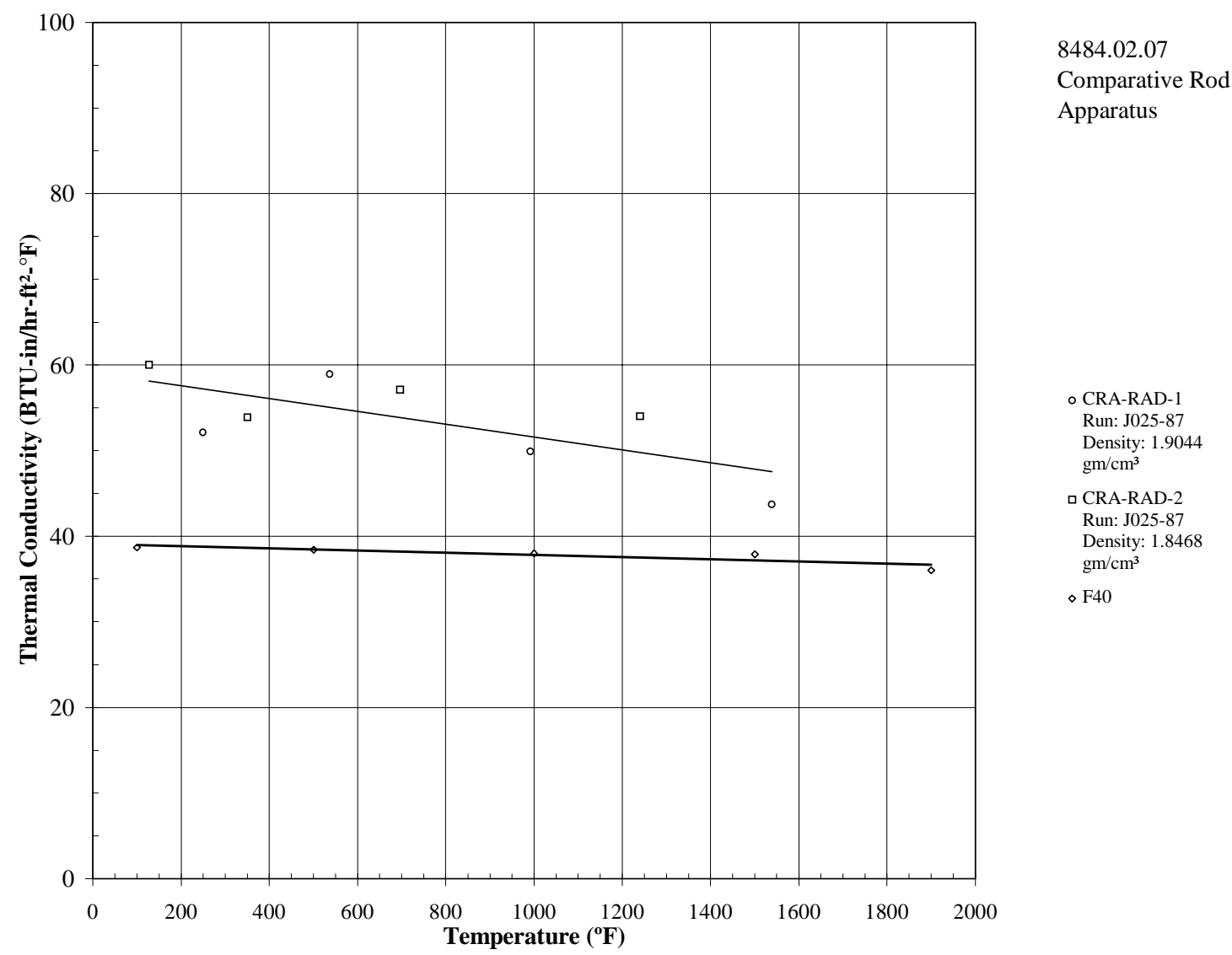

Figure 9. Thermal conductivity of as-manufactured Scumacher FT20 in the radial direction.

Microstructural examinations of Schumacher FT20 and Pall 326 are still in progress, but the initial findings are presented here. Photomicrographs taken at 200X of Schumacher FT20, as-manufactured and after $1166 \mathrm{hr}$. in service at Karhula, are shown in Figures 10 and 11. The photomicrographs indicate that this material consists of $\mathrm{SiC}$ particles connected by bridges of ceramic binder material. The binder does not typically cover the entire perimeter of the $\mathrm{SiC}$ particles but rather forms a bridge between adjacent particles. Small pores and cracks can be seen throughout the binder material. Pores and cracks in the binder weaken the candle filters although the structure, individual particles connected by bridges of matrix, provide an inherent "toughness" since cracks cannot propagate readily. The pores seen in the binder have curved boundaries with no sharp corners. This is typical of amorphous materials like glass whereas pores formed in crystalline materials typically have straight edges and sharp corners.

A cube of FT20 measuring 1/4 - 3/8 inch on each side was placed in hydrofluoric acid and within $2 \mathrm{hr}$. at $70^{\circ} \mathrm{F}$ the binder material was removed. The binder appears to be a non- 
translucent clay with alumina and some free glass (free silica). The photomicrograph of FT20 after $1166 \mathrm{hr}$. in service shows evidence of chemical attack around the edges of the binder material. Some pores in the binder after service at Karhula are open on the edges of the binder. These open edge pores and the rough surface are evidence of chemical attack around the edges of the binder. These photomicrographs show that, like the properties of Schumacher F40, properties of FT20 are controlled by the properties of the binder. Alumina was found by energy dispersive spectroscopy (EDS) of the solid and by diffraction of binder residue after reaction with hydrofluoric acid. Also, there were white particles in the residue after reaction with hydrofluoric acid. The free silica in the FT20 binder means the characteristics of clay, including high temperature creep and susceptibility to chemical attack in the PFBC environment, will be seen in this material; however, property measurements and microstructural examination both indicate that Schumacher FT20 showed improvements over Schumacher F40.

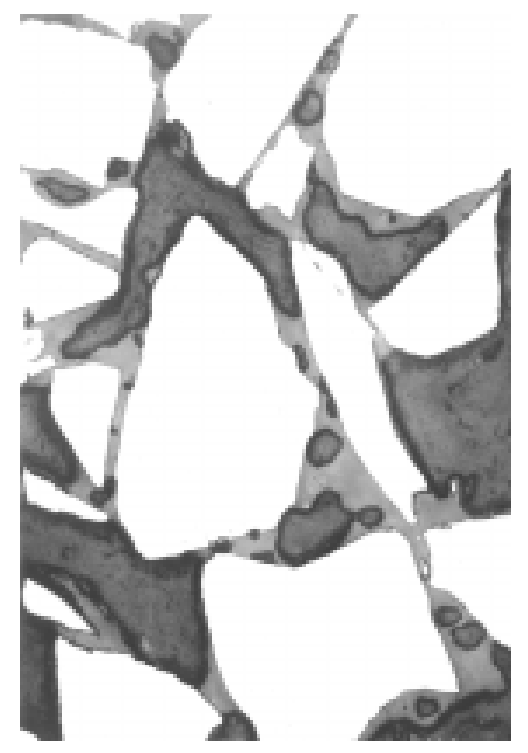

Figure 10. Photomicrograph taken at 200X of as-manufactured Schumacher FT20.

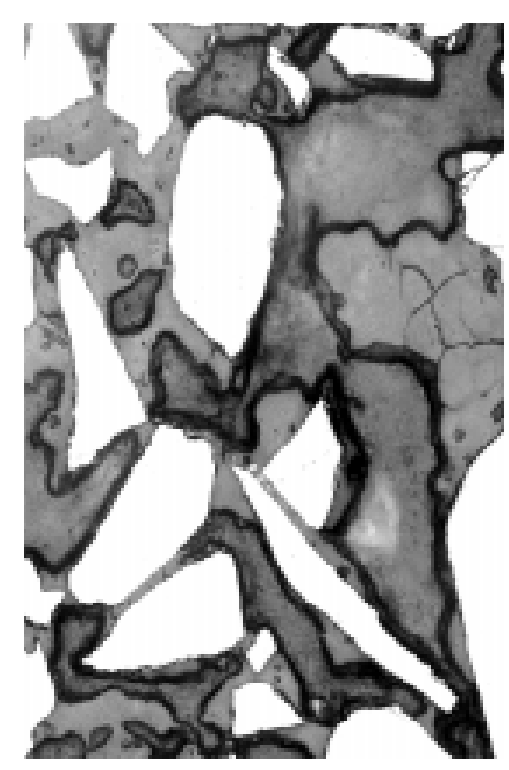

Figure 11. Photomicrograph taken at $200 \mathrm{X}$ of Schumacher FT20 after $1166 \mathrm{hr}$. in service at Karhula.

Pall 326

Axial tensile stress-strain responses at room temperature are shown in Figure 12 for Pall 326 as-manufactured, after $540 \mathrm{hrs}$. at $1560{ }^{\circ} \mathrm{F}$ in service, and after $1166 \mathrm{hrs}$. at $1560{ }^{\circ} \mathrm{F}$ in service. As seen in the Schumacher FT20 specimens, the stress-strain responses for asmanufactured specimens were nearly linear to failure but became nonlinear after service at Karhula, perhaps caused by matrix compliance due to lost binder material and matrix cracking. The specimens tested after $1166 \mathrm{hr}$. in service rolled over more than the specimens tested after $540 \mathrm{hr}$. in service. Room temperature tensile strengths in both the axial and hoop directions are plotted versus time in service in Figure 13. In the hoop direction, the tensile strength decreased $\sim 33 \%$, from 2130 psi to 1430 psi, after $540 \mathrm{hr}$. in service. In the axial direction, the tensile strength decreased $\sim 14 \%$, from 1150 psi to 990 psi, after $540 \mathrm{hr}$. in 
service and decreased $\sim 25 \%$, to 860 psi, after $1166 \mathrm{hr}$. in service. Considerable specimen-tospecimen variability was seen in tensile strength. One as-manufactured specimen had an axial strength of $1990 \mathrm{psi}, \sim 73 \%$ more than the other specimens. This strength value is not included in the average value of 110 psi discussed above. In comparison with Schumacher FT20, the strength of Pall 326 degrades more with time in the hot gas filtration environment. After 1166 hr., the strength of Schumacher FT20 appears to have leveled off (quit decreasing) whereas the strength of Pall 326 may decrease further with additional time in service. Because Pall 326 has a higher as-manufactured tensile strength than Schumacher FT20, the two materials have nearly the same axial strength after $1166 \mathrm{hr}$. in service even though the strength degradation was greater for Pall 326.

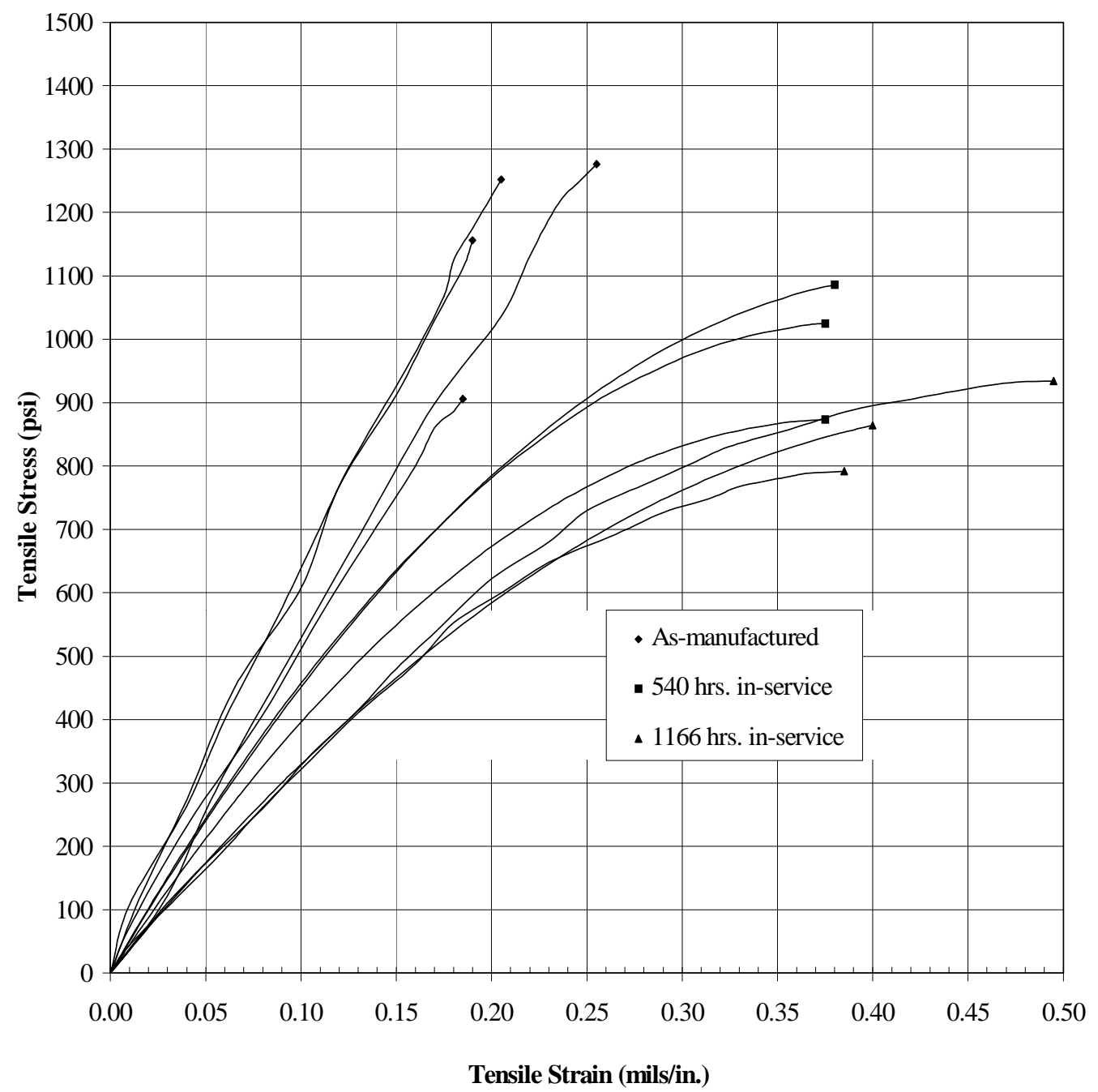

Figure 12. Tensile stress-strain responses at room temperature for Pall 326. 


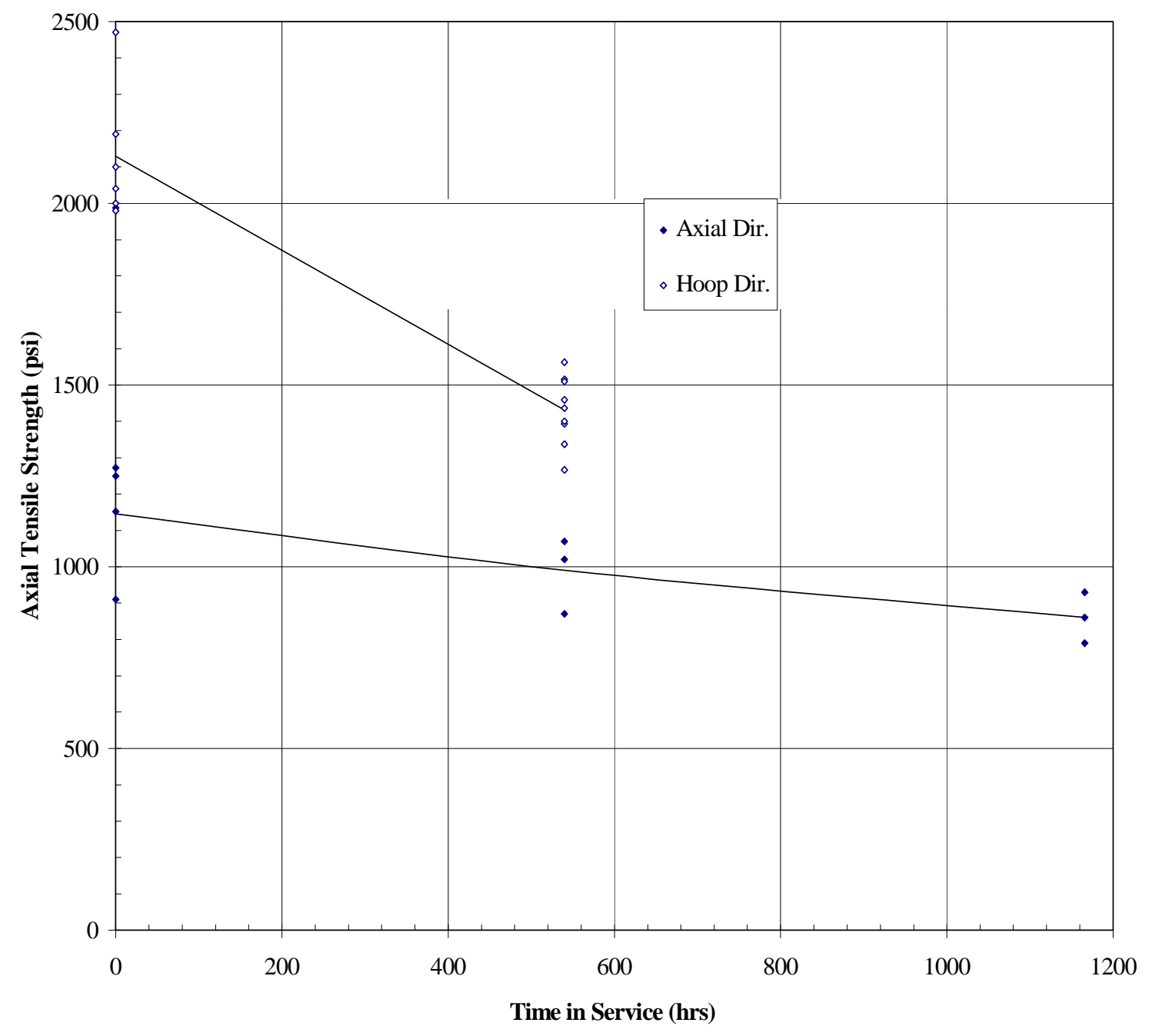

Figure 13. Ultimate tensile strength versus time in service for Pall 326.

Creep strain versus time responses obtained for Pall 326 are shown in Figure 14. The responses were similar for Schumacher FT20 and Pall 326; that is, the responses consisted of an initial region and a secondary region with the creep rate about an order of magnitude greater in the initial region. Two specimens were tested with tensile loads of 200 and $250 \mathrm{psi}$ at temperatures of $1500{ }^{\circ} \mathrm{F}$ to $1800{ }^{\circ} \mathrm{F}$ and no creep was measured. The remaining specimens, including all of those shown in Figure 14, were tested with a tensile load of 500 psi. While there was substantial specimen-to-specimen variability, the initial creep rates at $1600^{\circ} \mathrm{F}, 500 \mathrm{psi}$ were typically $10^{-5}-10^{-4} \mathrm{in}$./in. and the secondary creep rates at that temperature and stress level were typically an order of magnitude lower. These creep rates were similar to the values obtained for Schumacher FT20. Creep results obtained for three Pall 442T specimens are included in Figure 14 for comparison. Digitized curves were not available for these three $442 \mathrm{~T}$ specimens so only the endpoints are plotted. As shown, the creep rate of $442 \mathrm{~T}$ at $1550{ }^{\circ} \mathrm{F}, 200$ psi was similar to the creep rate of 326 at $1600{ }^{\circ} \mathrm{F}, 500$ psi. The Pall specimens were not as susceptible to breaking as the Schumacher specimens. 
One specimen broke at $1700^{\circ} \mathrm{F}, 500$ psi after $179 \mathrm{hrs}$. and one specimen broke (in the grip area) at $1800{ }^{\circ} \mathrm{F}, 500 \mathrm{psi}$ after $134 \mathrm{hr}$.. However, stress rupture was again active.

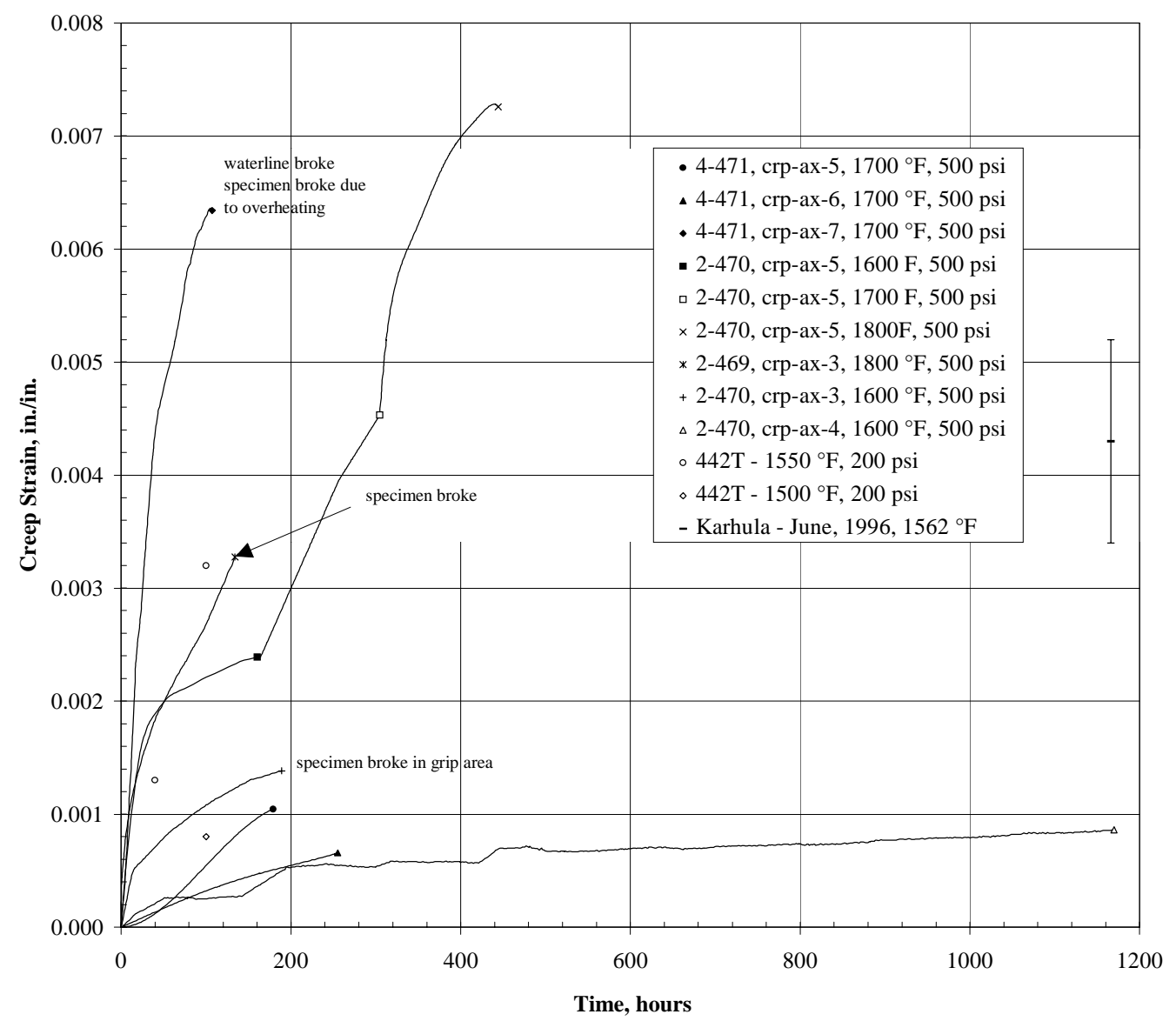

Figure 14. Creep strain versus time for Pall 326.

The 5 - $8 \mathrm{~mm}$ elongation reported by Westinghouse for candle filters removed from Karhula in November, 1996 after $1166 \mathrm{hrs}$. at $1560^{\circ} \mathrm{F}$ is plotted in Figure 14. Only one Pall creep specimen has been tested this long, and the total creep measured was less than was measured after service in Karhula. If the results of the $200 \mathrm{hr}$. creep tests are extrapolated to $1166 \mathrm{hrs}$. (a considerable extrapolation), the total creep would be near the values measured after removal from Karhula. Since the creep tests were conducted with a 500 psi load, and the load at Karhula, although it was unknown, was not likely that high, the elongations seen after service at Karhula appear greater than would be predicted based on creep strains measured in creep tests. This indicates that the PFBC environment affected the creep behavior. Creep testing on material removed after PFBC service at Karhula is in progress to determine the effect of this environment.

Unit thermal expansion of Pall 326 and 442T are shown in Figure 15. The "knee" in thermal expansion curve which was seen for Schumacher FT20 at $300{ }^{\circ} \mathrm{F}$ to $500{ }^{\circ} \mathrm{F}$ was seen for Pall 326 also. Return to zero on cool-down indicates that the knee in the curve probably represents a reversible phase transformation. From $500{ }^{\circ} \mathrm{F}$ up, the shape of the thermal 
curves for 326 and $442 \mathrm{~T}$ were similar; therefore, the materials have nearly the same coefficient of thermal expansion (CTE) in the operating range. A small knee in the thermal expansion curve for Pall 326 was seen at $1400^{\circ} \mathrm{F}$, possibly indicating the formation of tridymite or cristobalite in the binder material at this temperature. This was not seen in any of the other materials tested in this program.

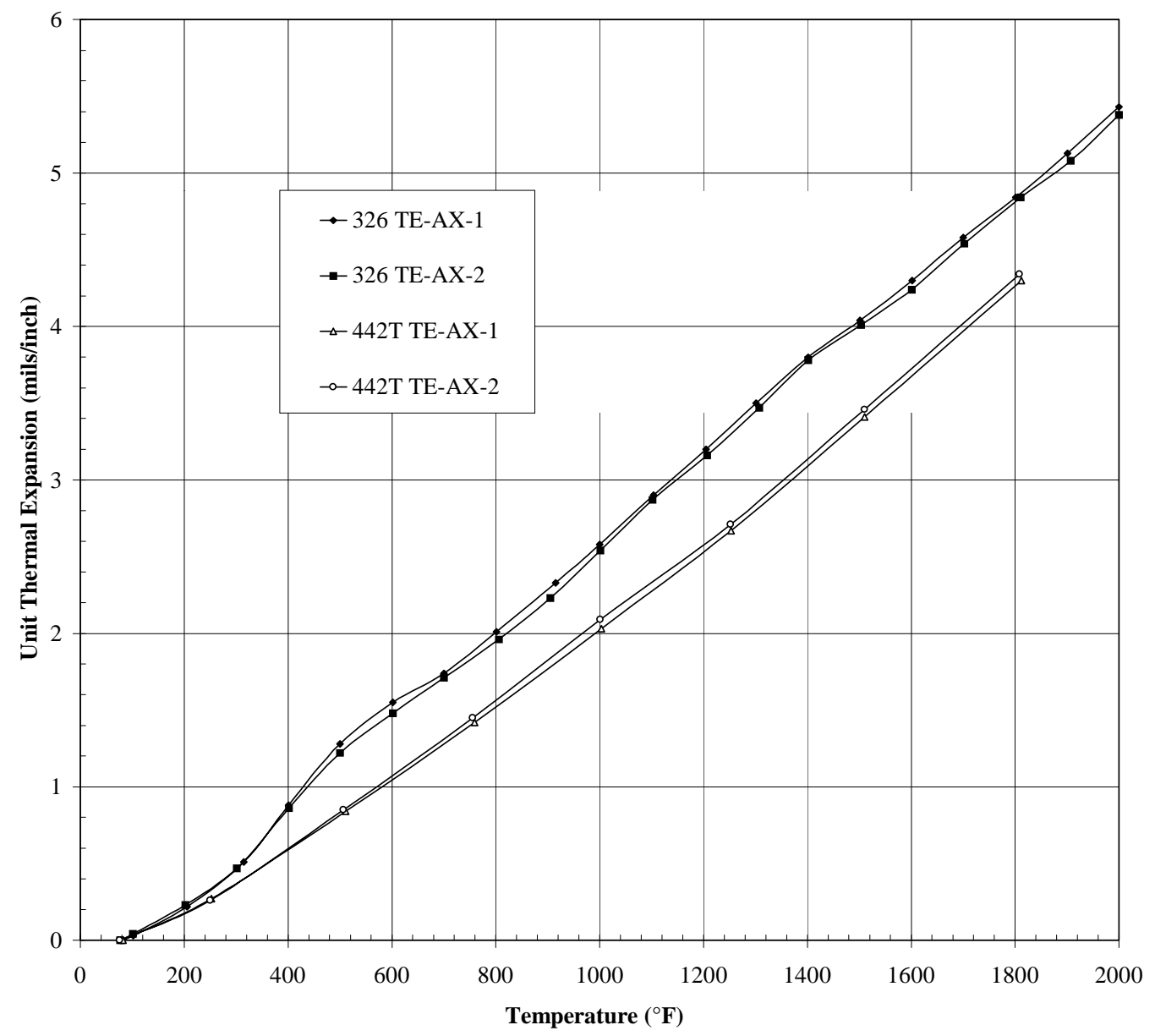

Figure 15. Unit thermal expansion of Refractron 326 and 442T.

Thermal conductivity of as-manufactured Pall 326 is plotted versus temperature in Figure 16. Thermal conductivity of as-manufactured Schumacher F40 is included for comparison. As

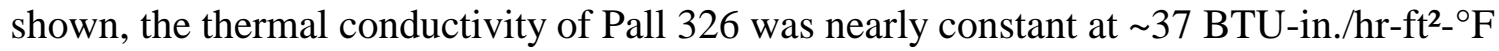
from $\sim 150{ }^{\circ} \mathrm{F}$ to $1200{ }^{\circ} \mathrm{F}$ and then decreased with temperature to $\sim 30.5 \mathrm{BTU}$-in. $/ \mathrm{hr}-\mathrm{ft}^{2}{ }^{\circ} \mathrm{F}$ at $1950{ }^{\circ} \mathrm{F}$. 


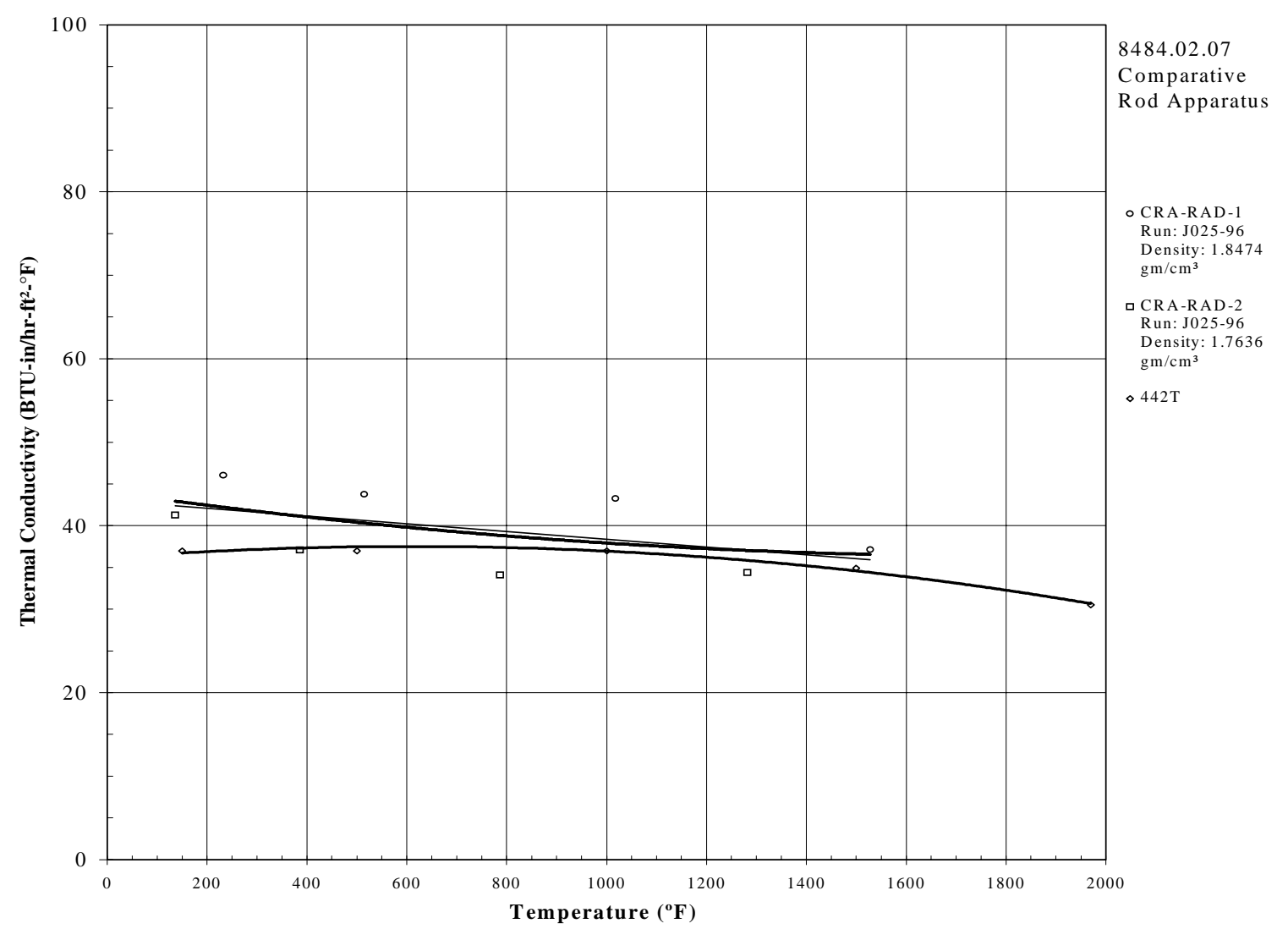

Figure 16. Thermal conductivity of as-manufactured Pall 326 in the radial direction.

Photomicrographs taken at $200 \mathrm{X}$ of Pall 326, as-manufactured and after $1166 \mathrm{hrs}$. in service at Karhula, are shown in Figures 17 and 18. The photomicrographs indicate that clusters of SiC particles were fully, or nearly fully, coated by the binder, and bridges connected these clusters. Numerous small pores and cracks are seen throughout the binder material, although, as with Schumacher materials, the structure of this material does not readily propagate cracks.

The pores in the 326 binder have curved boundaries with no sharp corners, typical of amorphous materials like glass. A cube of Pall 326 measuring 1/4 - 3/8 inch on each side was placed in hydrofluoric acid at $70{ }^{\circ} \mathrm{F}$ and within $2 \mathrm{hr}$. the binder was removed. Small scattered white particles were observed in the residue after reaction with hydrofluoric acid and alumina was seen in EDS. The binder appears to be a non-translucent clay with alumina and some free glass (free silica). Photomicrographs of Pall 326 after 1166 hr. at Karhula show evidence of chemical attack around the binder as well as increased cracking within the binder. Some pores in the binder after service at Karhula are open on the edges of the binder, evidence of chemical attack around the edges of the binder. As with the previously tested Pall 442T, the behavior of Pall 326 is controlled by the properties of the binder. Free silica in the 326 binder will lead to high temperature creep and susceptibility to chemical attack in the PFBC environment; however, property measurements and microstructural evaluations both indicate that Pall 326 showed improvements over Pall 442T. 


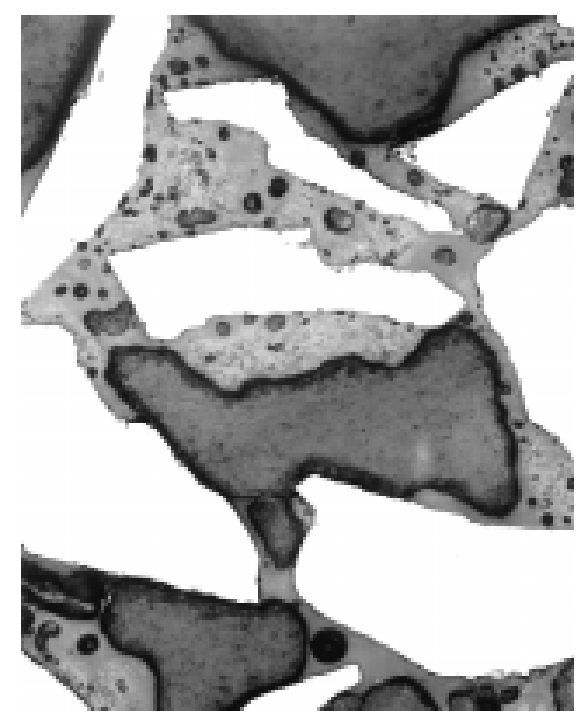

Figure 17. Photomicrograph taken at 200X of as-manufactured Pall 326.

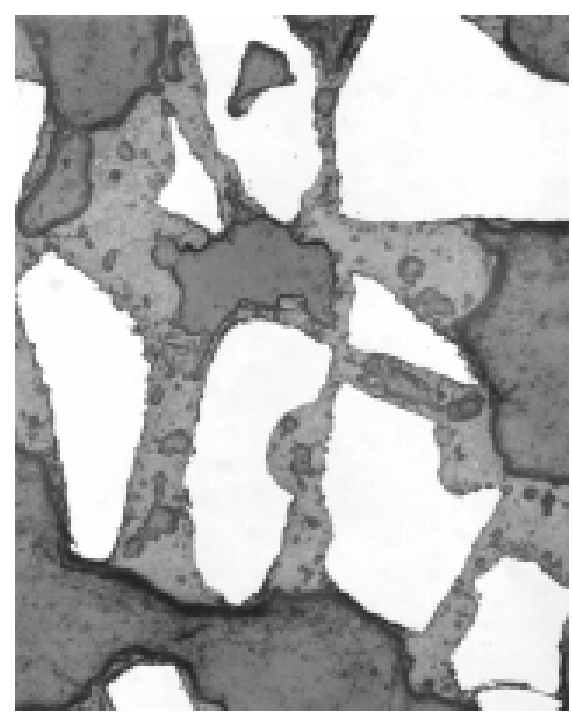

Figure 18. Photomicrograph taken at $200 \mathrm{X}$ of Pall 326 after $1166 \mathrm{hr}$. in service at Karhula.

\section{Task 2: Conclusions}

Based on test results the following conclusions were obtained:

Schumacher FT20 and Pall 326 have lower room temperature tensile strengths than Schumacher F40 and Pall 442T, but in the operating range of $1400{ }^{\circ} \mathrm{F}$ to $1600{ }^{\circ} \mathrm{F}$ the tensile strengths are near the same.

Property degradation in the PFBC environment is less severe for Schumacher FT20 and Pall 326 than for Schumacher F40 and Pall 442T. Schumacher FT20 lost less than $10 \%$ of its room temperature tensile strength after service at Karhula and Pall 326 lost from 15\% to 30\% of its tensile strength after service at Karhula.

Creep rates were about an order of magnitude lower for Schumacher FT20 and Pall 326 than for Schumacher F40 and Pall 442T, and creep began to occur at $100{ }^{\circ} \mathrm{F}$ to $200{ }^{\circ} \mathrm{F}$ higher temperature; however, creep and stress rupture persisted.

Microscopic examination indicated that properties of the binder control the behavior of Schumacher FT20 and Pall 326 and that the binder in both materials contains free silica. Therefore, high temperature creep and property degradation due to chemical attack in the PFBC environment will occur in these materials.

Chemical attack around the edges of the binder was evident in Schumacher FT20 and Pall 326 in photomicrographs after $1166 \mathrm{hrs}$. in service at Karhula. 


\section{FUTURE WORK}

There are also reasons to believe that portions of the mechanism describing deposit consolidation may apply to deposits of gasification particulate, although experimental verification must be carried out on appropriate samples collected from filters applied to this process. Laboratory analyses are also planned to further verify and characterize this mechanism, as well as to specifically identify the compounds that are involved in the formation of interparticle melts. One ultimate goal of this type of investigation may be the pursuit of some means of preventing ash deposits that do remain in filter vessels for long periods of time after undergoing this consolidation. However, give the nature of the consolidation mechanism, it is possible that the only feasible solution to this problem will be to limit time of exposure of ash deposits to the elevated temperatures found in the APF.

The filter vessel downstream of the M.W. Kellogg reactor train at the PSDF will be opened again in late July. At that time samples will be obtained for analysis and inclusion in the HGCU data base. Results of the analyses of those samples will be included in the next quarterly report. As mentioned earlier in this report, additional baking tests are planned for PFBC ashes from Tidd and Karhula, and possibly the PSDF.

Future testing of Schumacher FT20 and Pall 326 will focus on determining operating limits, including maximum temperature, load level, and time in service. Tensile evaluations will be used to assess property degradation in the PFBC environment. Creep tests on asmanufactured and used filters will be used to assess load and temperature levels where this material can operate without creep failure. Microstructural examinations including energy dispersive $\mathrm{x}$-ray analysis and $\mathrm{x}$-ray diffraction of residual binder material after dissolving in hydrofluoric acid will be used to better define the chemical properties of the binder. Higher magnification photomicrographs and scanning electron microscopy (SEM) will be used to examine the integrity of the particle/binder interface. Some Coors alumina mullite which was in service at Karhula for $1166 \mathrm{hr}$. is available and will be tested in the upcoming quarter to evaluate residual properties and degradation of this material in the hot gas cleanup environment. If any new materials become available for testing, this may be accomplished in the coming quarter also. 


\section{REFERENCES}

1. Raask, E., Mineral Impurities is Coal Combustion: Behavior, Problems, and Remedial Measures. Washington: Hemisphere Publishing Corporation, 1985.

2. Snyder, T.R. and D.H. Pontius, Updated Assessment of Ash Characteristics from Gas Stream Cleanup Facilities: October 1993 - August 1994, U.S. DOE Contract No. DEAC21-89MC26239 -Topical Report (Draft Version), 1994.

3. Levin, E.M., C.R. Robbins, and H.F. McMurdie, Phase Diagrams for Ceramists. Columbus: The American Ceramic Society, Inc., 1964.

4. Frankel, J.J., "Viscous flow of crystalline bodies under the action of surface tension," Jour. Phys. (Moscow) 9: 385 (1945). 


\title{
PARTICULATE HOT GAS STREAM CLEANUP TECHNICAL ISSUES
}

\author{
QUARTERLY REPORT
}

April 1997 - June 1997

\section{SRI-ENV-97-8484-Q11}

Contract No. DE-AC21-94MC31160

October 23, 1997

Approved by

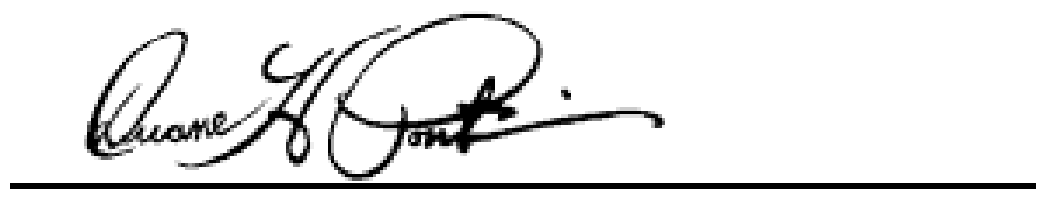

Duane H. Pontius, Director Particulate Sciences Department 